AperTO - Archivio Istituzionale Open Access dell'Università di Torino

\title{
Ceftolozane/tazobactam: place in therapy
}

\section{This is the author's manuscript}

Original Citation:

Availability:

This version is available http://hdl.handle.net/2318/1686331

since 2019-01-09T16:24:46Z

Published version:

DOI: $10.1080 / 14787210.2018 .1447381$

Terms of use:

Open Access

Anyone can freely access the full text of works made available as "Open Access". Works made available under a Creative Commons license can be used according to the terms and conditions of said license. Use of all other works requires consent of the right holder (author or publisher) if not exempted from copyright protection by the applicable law. 


\title{
Ceftolozane/tazobactam: place in therapy
}

\author{
Daniele Roberto Giacobbe, Matteo Bassetti, Francesco Giuseppe De Rosa, \\ Valerio Del Bono, Paolo Antonio Grossi, Francesco Menichetti, Federico Pea, \\ GianMaria Rossolini, Mario Tumbarello, Pierluigi Viale \& Claudio Viscolion \\ behalf of ISGRI-SITA (Italian Study Group on Resistant Infection of the \\ Società Italiana Terapia Antinfettiva)
}

To cite this article: Daniele Roberto Giacobbe, Matteo Bassetti, Francesco Giuseppe De Rosa, Valerio Del Bono, Paolo Antonio Grossi, Francesco Menichetti, Federico Pea, GianMaria Rossolini, Mario Tumbarello, Pierluigi Viale \& Claudio Viscolion behalf of ISGRI-SITA (Italian Study Group on Resistant Infection of the Società Italiana Terapia Antinfettiva) (2018): Ceftolozane/tazobactam: place in therapy, Expert Review of Anti-infective Therapy

To link to this article: https://doi.org/10.1080/14787210.2018.1447381

Accepted author version posted online: 01 Mar 2018.

Submit your article to this journal 지

Q View related articles $₫$

View Crossmark data $\nearrow$ 


\section{Review}

\section{Ceftolozane/tazobactam: place in therapy}

Daniele Roberto Giacobbe ${ }^{1 *}$ Matteo Bassetti ${ }^{2}$, Francesco Giuseppe De Rosa ${ }^{3}$, Valerio Del Bono $^{1}$, Paolo Antonio Grossi ${ }^{4}$, Francesco Menichetti ${ }^{5}$, Federico Pea ${ }^{6}$, GianMaria Rossolini ${ }^{7,8}$, Mario Tumbarello ${ }^{9}$, Pierluigi Viale ${ }^{10}$, Claudio Viscoli ${ }^{1}$, on behalf of ISGRI-SITA (Italian Study Group on Resistant Infection of the Società Italiana Terapia Antinfettiva)

${ }^{1}$ Infectious Diseases Unit, Ospedale Policlinico San Martino - IRCCS per 1'Oncologia and Department of Health Sciences, University of Genoa, Genoa, Italy

2 Infectious Diseases Clinic, Department of Medicine, University of Udine and Azienda Sanitaria Universitaria Integrata Presidio Ospedaliero Universitario Santa Maria della Misericordia, Udine, Italy

${ }^{3}$ Department of Medical Sciences, University of Turin, Infectious Diseases, City of Health and Sciences, Turin, Italy

4 Department of Surgical and Morphological Sciences of Clinical Medicine, University of Insubria, Varese, Italy

${ }^{5}$ Infectious Diseases Clinic, Nuovo Santa Chiara University Hospital, Azienda Ospedaliera Universitaria Pisana, Pisa, Italy

${ }^{6}$ Institute of Clinical Pharmacology, Azienda Sanitaria Universitaria Integrata Presidio Ospedaliero Universitario Santa Maria della Misericordia, Udine, Italy

${ }^{7}$ Department of Experimental and Clinical Medicine, University of Florence, Florence, Italy.

${ }^{8}$ Clinical Microbiology and Virology Unit, Florence Careggi University Hospital, Florence, Italy.

9 Institute of Infectious Diseases, Università Cattolica del Sacro Cuore, Fondazione Policlinico Universitario Agostino Gemelli, Rome, Italy

${ }^{10}$ Department of Medical and Surgical Sciences, University of Bologna, Bologna, Italy. 
* Corresponding author:

Daniele Roberto Giacobbe

Ospedale Policlinico San Martino - IRCCS per l'Oncologia

Department of Health Sciences, University of Genoa

L.go R. Benzi, 10 - 16132 Genoa, Italy

Telephone: +39 010555 4658; Fax: +39010 5556606

Mail address: daniele.roberto.giacobbe@gmail.com 


\begin{abstract}
Introduction: Ceftolozane/tazobactam $(\mathrm{C} / \mathrm{T})$ is a new antibiotic resulting from the combination of a novel cephalosporin, structurally similar to ceftazidime, with tazobactam, a well-known beta-lactamase inhibitor. $\mathrm{C} / \mathrm{T}$ remains active against extended-spectrum $\beta$ lactamase (ESBL)-producing Enterobacteriaceae and multi-drug resistant (MDR) $P$. aeruginosa, and has been recently approved for the treatment of complicated intra-abdominal infections (cIAI) and complicated urinary infections (cUTI). A trial on hospital-acquired pneumonia is ongoing.
\end{abstract}

Areas covered: The place in therapy of $\mathrm{C} / \mathrm{T}$ is delineated by addressing the following main topics: (i) antimicrobial properties; (ii) pharmacological properties; (iii) results of clinical studies.

Expert commentary: $\mathrm{C} / \mathrm{T}$ is approved for CIAI and cUTI. However, the drug has a special value for clinicians in any kind of infectious localization for two main reasons. The first is that $\mathrm{C} / \mathrm{T}$ is especially valuable in suspected or documented severe infections due to MDR $P$. aeruginosa, which is not a rare occurrence in many countries. The second is that $\mathrm{C} / \mathrm{T}$ may provide an alternative to carbapenems for the treatment of infections caused by ESBLproducers, thus allowing a carbapenem-sparing strategy. Reporting of off-label use is mandatory to increase the body of evidence and the clinicians' confidence in using it for indications other than cIAI and cUTI.

Key words: antimicrobial resistance; MDR; ceftolozane; tazobactam; carbapenem-sparing; ESBL; Pseudomonas; Enterobacteriaceae. 


\section{Introduction}

In the last decade, we have witnessed a dramatic increase worldwide in the number of multidrug resistant (MDR) Gram-negative bacteria, with extended-spectrum $\beta$-lactamase (ESBL)-producing Enterobacteriaceae and MDR-Pseudomonas aeruginosa among the main threats in clinical practice [1-4]. Due to resistance to third generation cephalosporins and, at least in part, to piperacillin-tazobactam, the most common antibiotics prescribed as empiric regimens, the presence of these MDR bacteria has forced many centers to shift to carbapenems as initial empirical therapy in critically ill patients, in order not to put the patient at risk of delaying the initiation of an active antibiotic therapy $[5,6]$. This has probably contributed to the spread of carbapenem resistance, within a vicious circle of forced indiscriminate prescription of carbapenems and further resistance selection $[5,7,8]$. Carbapenem-sparing regimens have thus been advocated as a possible mean to decrease the spread of carbapenem resistance and possible to restitute activity to carbapenems [9].

Ceftolozane/tazobactam $(\mathrm{C} / \mathrm{T})$ is the combination of a novel cephalosporin, structurally similar to ceftazidime, with a well-known $\beta$-lactamase inhibitor [10]. C/T has shown activity against MDR $P$. aeruginosa and ESBL-producing Enterobacteriaceae, and has been recently approved for the treatment of complicated intra-abdominal infections (cIAI) and complicated urinary infections (cUTI), including pyelonephritis, by the U.S. Food and Drug Administration (FDA) and the European Medicines Agency (EMA) [11, 12]. In this article, we will review the pharmacological and antimicrobial features of this new antibiotic, and discuss both its current place in the antibiotic armamentarium and its possible future positioning in so far unapproved indications for suspected and proven infections due to MDR Gram-negative bacteria.

\section{Methods}


In a round of discussions in May 2017, the following main topics were identified to be addressed in this narrative review: (i) antimicrobial properties; (ii) pharmacological properties; (iii) results of clinical studies. Subsequently, relevant publications were searched through the MEDLINE/PubMed database, using dedicated keywords for each topic. The next step was the production of separated preliminary drafts by different groups of authors, each addressing one of the topics. In October 2017, the preliminary drafts were merged and organized in a final manuscript, which was finally reviewed by all authors.

\section{Antimicrobial properties}

\subsection{Mechanism of action}

Ceftolozane (previously CXA-101 and FR-264205) is a novel expanded-spectrum cephalosporin with potent activity against Pseudomonas aeruginosa and other Gram-negative pathogens. As with all $\beta$-lactams, the antibacterial activity is due to inhibition of the penicillin-binding proteins (PBPs) involved in the final steps of peptidoglycan biosynthesis.

The ceftolozane molecule is an oxyimino-cephalosporin which differs from ceftazidime mostly by the presence of a bulkier side chain at the 3-position of the dihydrothiazine ring (Figure 1). This modification entails a higher affinity and a broader inhibition profile toward the essential PBPs of P. aeruginosa (e. g. PBP1b, PBP1c, PBP2 and PBP3) compared to ceftazidime, while the affinity to PBP4 remains lower than that of imipenem and thus unable to induce AmpC overexpression [13]. Due to this modification, ceftolozane is also more stable to the chromosomal AmpC $\beta$-lactamase of $P$. aeruginosa [1416] and is an overall poor substrate of the Mex efflux pumps found in this species [17]. Thanks to these features and to the fact that, unlike carbapenems, entry across the outer membrane of $P$. aeruginosa is not affected by functionality of the OprD porin $[17,18]$, ceftolozane exhibits an anti-Pseudomonas activity which is overall superior than that of other 
anti-Pseudomonas $\beta$-lactams (see below, surveillance data), and was also demonstrated against strains grown in biofilms [19, 20].

Similar to ceftazidime and other expanded-spectrum cephalosporins, ceftolozane is not stable to extended-spectrum $\beta$-lactamases (ESBLs). For this reason, the formulation for clinical use has been developed in combination with tazobactam, a mechanism-based $\beta$ lactamase inhibitor which extends the activity of ceftolozane against many ESBL-producing Enterobacteriaceae and some Bacteroides spp. [21, 22].

\subsection{Spectrum of activity and surveillance data}

The spectrum of activity of $\mathrm{C} / \mathrm{T}$ is mostly oriented toward Gram-negative pathogens, including Enterobacteriaceae and P. aeruginosa. In vitro activity has also been documented against Haemophilus, and Moraxella, and also against some strains of Acinetobacter, Stenotrophomonas, Burkholderia and other nonfastidious Gram-negative nonfermenters, although the clinical utility for infections caused by these pathogens remains to be established [23-25]. Among Gram-positives, $\mathrm{C} / \mathrm{T}$ is active against $\beta$-hemolytic streptococci (Streptococcus pyogenes and Streptococcus agalactiae), and also exhibits some activity against pneumococci, while it is not active against staphylococci and enterococci [25]. Finally, $\mathrm{C} / \mathrm{T}$ has no activity against most anaerobic bacteria, including Clostridium difficile, with the possible exception of some Bacteroides spp strains. [25-27].

The activity of $\mathrm{C} / \mathrm{T}$ against clinical isolates of Enterobacteriaceae and P. aeruginosa has been evaluated by several surveillance studies carried out in different settings. Results from a selection of recent surveillance studies are summarized in Table 1 [25, 28-38]. Altogether, in these studies, $\mathrm{C} / \mathrm{T}$ was consistently found to be the most active $\beta$-lactam against $P$. aeruginosa, retaining remarkable activity also against MDR and extensively drugresistant (XDR) isolates, even when carbapenem-resistant in absence of carbapenemase 
production. Interestingly, outstanding anti-Pseudomonas activity of $\mathrm{C} / \mathrm{T}$ was also observed against isolates from cystic fibrosis patients, for whom mucoid strains of $P$. aeruginosa represents a major problem. Concerning Enterobacteriaceae, the in vitro activity of $\mathrm{C} / \mathrm{T}$ was consistently higher than that of ceftazidime and cefepime, and also of piperacillin/tazobactam, but lower than that of meropenem. Concerning ESBL producers, the activity of $\mathrm{C} / \mathrm{T}$ was overall superior than that of piperacillin/tazobactam, and higher against Escherichia coli than against Klebsiella pneumoniae. On the other hand, C/T was consistently not active against carbapenem-resistant Enterobacteriaceae (CRE).

\subsection{Mechanisms of resistance}

Acquired resistance to $\mathrm{C} / \mathrm{T}$ has been reported in clinical isolates of $P$. aeruginosa producing $\beta$-lactamases which degrade ceftolozane and are not efficiently inhibited by tazobactam (e. g. metallo- $\beta$-lactamases, GES-type enzymes, or OXA-type ESBLs) [25, 39, 40]. Mutations in the resident AmpC $\beta$-lactamase, possibly associated with overexpression of the enzyme, were also shown to be responsible for increased ceftolozane/tazobactam MICs following in vitro exposure to increasing drug concentrations [41] or even following clinical use, and some highly resistant strains have been described [42-44]. However, the propensity for selection of mutational resistance appears to be generally low, and significantly lower than that observed with other anti-Pseudomonas agents (e. g. meropenem, ceftazidime and ciprofloxacin) [41].

In Enterobacteriaceae, a major mechanism of acquired resistance to $\mathrm{C} / \mathrm{T}$ is represented by the production of carbapenemases that can degrade ceftolozane and are not efficiently inhibited by tazobactam (e. g. metallo- $\beta$-lactamases [MBL], KPC, GES). In fact, carbapenemase-producing Enterobacteriaceae (CPE) are usually non-susceptible to ceftolozane/tazobactam (Table 1). However, OXA-48 producers may remain susceptible since ceftolozane is stable to this enzyme and co-produced ESBLs, if present, are inhibited by 
tazobactam [25]. ESBL and AmpC producers are variably susceptible to $\mathrm{C} / \mathrm{T}$, depending on the bacterial species and enzyme types $[21,25]$.

\subsection{Susceptibility testing}

Susceptibility testing of $\mathrm{C} / \mathrm{T}$ is important since resistant isolates of $P$. aeruginosa and Enterobacteriaceae can be encountered due to various resistance mechanisms (see above).

Somewhat different clinical breakpoints have been released by the Clinical and Laboratory Standards Institute (CLSI) and the European Committee on Antimicrobial Susceptibility Testing (EUCAST). CLSI breakpoints for $P$. aeruginosa are $\mathrm{S} \leq 4$ and $\mathrm{R}>8$ $\mathrm{mg} / \mathrm{L}$, while EUCAST breakpoints for the same pathogen are $\mathrm{S} \leq 4$ and $\mathrm{R}>4 \mathrm{mg} / \mathrm{L}[45,46]$. Breakpoints for Enterobacteriaceae are also different between CLSI and EUCAST (S $\leq 2$ and $\mathrm{R}>4$ Vs. $\mathrm{S} \leq 1$ and $\mathrm{R}>1 \mathrm{mg} / \mathrm{L}$, respectively) $[45,46]$. Of note, CLSI also provides specific breakpoints for viridans streptococci $(\mathrm{S} \leq 8, \mathrm{R}>16 \mathrm{mg} / \mathrm{L})$, while EUCAST considers the available evidence for setting breakpoints for streptococci insufficient despite the reported in vitro activity $[45,46]$. However, EUCAST provides $\mathrm{PK} / \mathrm{PD}$ breakpoints for $\mathrm{C} / \mathrm{T}(\mathrm{S} \leq 4, \mathrm{R}>4$ $\mathrm{mg} / \mathrm{L}$ ), which, although less robustly than classical breakpoints, suggest that $\mathrm{C} / \mathrm{T}$ might be useful also for treating infections due to microorganisms within its spectrum of activity other than $P$. aeruginosa and Enterobacteriaceae, provided their MIC is $\leq 4 \mathrm{mg} / \mathrm{L}$ [46].

Broth microdilution (BMD) is the reference method for susceptibility testing, and commercial systems for $\mathrm{C} / \mathrm{T}$ susceptibility testing by $\mathrm{BMD}$ are available from some manufacturers (e. g. Thermo Fisher Scientific, Merlin Diagnostika). Gradient diffusion tests have also been developed (Etest, bioMérieux; MIC test strips, Liofilchem) to facilitate susceptibility testing of $\mathrm{C} / \mathrm{T}$ in clinical microbiology laboratories. A recent evaluation of Etest with a collection of meropenem-resistant $P$. aeruginosa isolates, however, revealed 
high error rates in comparison with reference $\mathrm{BMD}$, with very high rates of false susceptibilities among the $\mathrm{C} / \mathrm{T}$ resistant isolates [47]. On the other hand, an evaluation of MIC test strips with a collection of MDR/XDR P. aeruginosa isolates revealed lower error rates in comparison with reference BMD, with no false susceptibilities [40]. Disk diffusion has been approved by FDA for C/T susceptibility testing, but its practical utility is limited since zone diameter clinical breakpoints are only available for $P$. aeruginosa and only from CLSI. However, a recent evaluation of a disk diffusion test (interpreted according to the CLSI breakpoints) with a collection of MDR/XDR $P$. aeruginosa isolates has revealed a good correlation with reference BMD (interpreted according to the EUCAST breakpoints), with no false susceptibilities [40].

Current evidence, therefore, would suggest the use of BMD for $\mathrm{C} / \mathrm{T}$ susceptibility testing, while waiting for a broader experience with gradient and disk diffusion tests. The implementation of the drug in validated panels of semiautomated systems, which is currently underway, is highly desirable.

\section{Pharmacological properties}

\subsection{Pharmacokinetics}

The pharmacokinetics of ceftolozane, alone and/or in combination with tazobactam, was assessed in healthy volunteers over a wide range of doses (ranging from 250 and $2000 \mathrm{mg}$ for ceftolozane and from 250 and $1000 \mathrm{mg}$ for tazobactam) [23, 48, 49]. After either single or multiple dose administration, the increases of Cmax and AUC were dose-proportional. The volume of distribution $(\mathrm{Vd})$, ranged between 11 and $18 \mathrm{~L}$ and reflected a distribution limited to the extracellular milieu, similarly to what occurred with other cephalosporins. The plasma protein binding was approximately $20 \%$, and the mean elimination half-life was $2-3 \mathrm{~h}$. Ceftolozane was almost completely cleared as unchanged moiety by the renal route (92\%). 
The pharmacokinetics of tazobactam are linear and not affected by co-administration with ceftolozane, which is different from what is observed during co-administration with piperacillin $[23,50]$.

The licensed dose of the $\mathrm{C} / \mathrm{T}$ in patients with normal renal function is $1000 / 500 \mathrm{mg}$ every $8 \mathrm{~h}$ infused intravenously over $1 \mathrm{~h}$. Dosages should be reduced in patients with impaired renal function (Table 2) [51]. The following dosages are recommended in relation to different classes of creatinine clearance (CLCr): 500/250 mg every $8 \mathrm{~h}$ in presence of CLCr 30-50 $\mathrm{mL} / \mathrm{min} ; 250 / 125 \mathrm{mg}$ every $8 \mathrm{~h}$ in presence of CLCr $15-29 \mathrm{~mL} / \mathrm{min} ; 100 / 50 \mathrm{mg}$ every $8 \mathrm{~h}$ after an initial loading dose of 500/250 $\mathrm{mg}$ in presence of end stage renal disease (ESRD) or during intermittent hemodialysis (IHD). In the latter case, the dose of $\mathrm{C} / \mathrm{T}$ should be given as soon as possible following completion of the hemodialytic procedure, because C/T can be removed by dialysis. No dosage adjustment is needed in presence of hepatic impairment.

Ceftolozane is not expected to have any clinically significant drug-drug interaction, since at therapeutic concentrations it is neither a substrate nor a modulator of the cytochrome P450 system $[49,52]$. Tazobactam is a substrate of the organic anion transporters 1 (OAT1) and 3 (OAT3), and the co-administration of drugs that may inhibit these transporters (e.g., probenecid) may increase its plasma concentrations [49].

\subsection{Pharmacokinetics in special patient populations}

The pharmacokinetics and tissue penetration of C/T 1000/500 mg every $8 \mathrm{~h}$ was assessed among 10 patients with diabetic foot infections and compared with healthy volunteers [53]. Tissue penetration was determined by means of microdialysis. The median (range) AUCtissue/AUCplasma ratio in patients with diabetic foot infection was 0.75 (0.35-1.00), with a mean (range) free time above $4 \mathrm{mg} / \mathrm{L}$ (namely the susceptibility breakpoint vs. $P$. aeruginosa) of $99.8 \%(87.5-100 \%)$. The penetration into subcutaneous tissues was similar in 
both patients with diabetic foot infection and healthy volunteers, and the authors concluded that $\mathrm{C} / \mathrm{T}$ at $1000 / 500 \mathrm{mg}$ every $8 \mathrm{~h}$ may achieve adequate exposure against susceptible pathogens in subcutaneous tissue of patients with diabetic foot infection.

The pharmacokinetics of $\mathrm{C} / \mathrm{T}$ in patients receiving continuous venovenous hemodiafiltration (CVVHDF) was described in two different case reports [54, 55]. In both cases $\mathrm{C} / \mathrm{T}$ was administered at $2000 / 1000 \mathrm{mg}$ every $8 \mathrm{~h}$. Whereas in one case ceftolozane elimination half-life was significantly prolonged (13.3h) compared to healthy volunteers [53], in the other one it was much lower $(4.7 \mathrm{~h})[55]$. C/T was significantly removed by this renal replacement therapy (CVVHDF clearance, $2.4 \mathrm{~L} / \mathrm{h}$ ) [54]. Even if these data are very preliminary, it would suggest that a standard dosage of $1000 / 500 \mathrm{mg}$ every $8 \mathrm{~h}$ should ensure appropriate exposure against pathogen with an MIC up to $8 \mathrm{mg} / \mathrm{L}$ for the treatment of pneumonia in patients undergoing CVVHDF [54].

\subsection{Pharmacodynamics}

The pharmacodynamic determinants of efficacy of ceftolozane, with and without tazobactam, were first tested against $P$. aeruginosa and Enterobacteriaceae in an experimental animal model in the thighs of neutropenic mice [56]. Similar to other beta-lactams, the percentage of time that the concentrations were maintained above the MIC $(\% \mathrm{~T}>\mathrm{MIC})$ was the best predictor of ceftolozane efficacy. The mean $\% \mathrm{~T}>\mathrm{MIC}$ needed for bacterial stasis was $24.0 \%$ against $P$. aeruginosa, 26.3\% against wild-type Enterobacteriaceae and 31.1\% against ESBLproducers. The mean $\% \mathrm{~T}>\mathrm{MIC}$ needed for $1-\log$ kill was $31.5 \%$ against $P$. aeruginosa, $31.6 \%$ against wild-type Enterobacteriaceae, and $34.8 \%$ against ESBL-producers. Noteworthy, these values of $\% \mathrm{~T}>\mathrm{MIC}$ were lower than those usually required by other cephalosporins, and the finding was attributed to a more rapid killing with ceftolozane. In the same study, it was shown that ceftolozane had faster rate of in vivo killing of $P$. aeruginosa 
than ceftazidime, and that the most potent combination with tazobactam against ESBLproducing Enterobacteriaceae could be obtained using a 2:1 ratio (2000 mg of ceftolozane and $1000 \mathrm{mg}$ of tazobactam) [56]. Similar results were recently obtained in an in vitro pharmacokinetic model of infection, against both E. coli and P. aeruginosa [57]. The $\% \mathrm{~T}>\mathrm{MIC}$ for 1-log and 2-log decrease in initial inoculum for E.coli were $33.0 \%$ and $39.6 \%$, respectively, and CTX-M-15 production did not affect this pharmacodynamic index [57]. For P. aeruginosa, the $\% \mathrm{~T}>\mathrm{MIC}$ for $1-\log$ and $2-\log$ decrease in initial inoculum were $26.6 \%$ and $31.2 \%$, respectively [57]. Concerning the desired drug exposure for ESBL producers, VanScoy et al. showed that, against CTX-M-15 producing E. coli, the mean \% $>$ MIC values for tazobactam needed for achieving bacteriostasis and 1- and 2-log bacterial kill were of 35.5 and $70 \%$, respectively $[58,59]$. Similar results were obtained by Soon et al. by testing $\mathrm{C} / \mathrm{T}$ against four strains of E.coli with different $\beta$-lactamase expression [60]. In a neutropenic mouse model, the main pharmacodynamic index that correlated with efficacy against ESBLproducing Enterobacteriaceae was the percentage of time above a tazobactam concentration threshold $(\mathrm{T}>\mathrm{CT})$ of $0.5 \mathrm{mg} / \mathrm{L}$ [61]. The mean \% $>\mathrm{CT}$ for static effect and 1-log kill was $28.2 \%$ and $44.4 \%$, respectively, at steady-state ceftolozane exposures maintaining concentration of $4 \mathrm{mg} / \mathrm{L}$ for 33.9 and $63.3 \%$ of a $24 \mathrm{~h}$ period [61]. 


\subsection{Monte Carlo simulation studies predicting efficacy in different patient populations}

A Monte Carlo simulation, based on data from a previously developed population pharmacokinetic model in which CLCr was a significant covariate [62], was performed in order to determine whether the currently recommended licensed dosages of $\mathrm{C} / \mathrm{T}$ may be adequate for optimal pharmacodynamic efficacy in patients with various degrees of renal function, including those with augmented renal clearance (ARC) and with ESRD [63]. Predicted probability of target attainment (PTA) with the different licensed dosages of C/T for $\mathrm{T}>\mathrm{MIC} 40 \%$ against Enterobacteriaceae and $P$. aeruginosa with an MIC for $\mathrm{C} / \mathrm{T}$ up to 4 $\mathrm{mg} / \mathrm{L}$ were optimal $(>90 \%)$ in patients with normal renal function and with renal impairment, and acceptable ( $>80 \%)$ in patients with ARC [63].

A recent pharmacokinetic/pharmacodynamic study focused on identifying the most suitable $\mathrm{C} / \mathrm{T}$ dose to be tested for phase 3 studies in patients with nosocomial pneumonia [64]. The rationale was based on the findings of a previous phase 1 study, which was carried out to assess the intrapulmonary penetration of $\mathrm{C} / \mathrm{T}$ after the administration of three doses of 1000/500 mg every 8 hours to healthy volunteers [65]. The study showed that the AUC in the epithelial lining fluid (ELF) was $48 \%$ of that observed in plasma [65]. Accordingly, Monte Carlo simulations with the licensed dosage of $1000 / 500 \mathrm{mg}$ every $8 \mathrm{~h}$ and also with a double dosage of $2000 / 1000 \mathrm{mg}$ every $8 \mathrm{~h}$ were performed in order to determine the PTA of adequate pharmacodynamic targets ( $\mathrm{T}>\mathrm{MIC} 24.8 \%, 32.2 \%$ and $40 \%$ ) in the ELF predicting optimal treatment against key pathogens responsible for nosocomial pneumonia (Enterobacteriaceae and $P$. aeruginosa). It was shown that doubling of the currently approved dose may be appropriate in patients with normal renal function in order to achieve PTA > $90 \%$ in ELF against $P$. aeruginosa with a MIC up to $8 \mathrm{mg} / \mathrm{L}$ for optimal treatment of nosocomial pneumonia [64]. 
The population pharmacokinetics of $\mathrm{C} / \mathrm{T}$ at 2000/1000 mg every $8 \mathrm{~h}$ was also assessed in a prospective, multicenter, open-label study carried out among 20 adult patients with cystic fibrosis and acute pulmonary exacerbations [66]. The rationale for testing this double dosage was based on the fact that cystic fibrosis patients frequently have altered pharmacokinetics of antimicrobials, with augmented clearance. Monte Carlo simulation were performed to determine the PTA of achieving $60 \% \mathrm{~T}>\mathrm{MIC}$ of $\mathrm{C} / \mathrm{T}$ at either $1000 / 500 \mathrm{mg}$ every $8 \mathrm{~h}$ or 2000/1000 mg every 8 h against $P$. aeruginosa, a pathogen frequently associated with these underlying conditions. It was shown that $\mathrm{C} / \mathrm{T}$ clearance estimates in cystic fibrosis were similar to those observed in non-cystic fibrosis patients. Monte Carlo simulation with $1000 / 500 \mathrm{mg}$ every $8 \mathrm{~h}$ and $2000 / 1000 \mathrm{mg}$ every $8 \mathrm{~h}$ predicted optimal PTA ( $>90 \%)$, in terms of T $>$ MIC $60 \%$, against $P$. aeruginosa with MIC up to 4 and $8 \mathrm{mg} / \mathrm{L}$, respectively [66].

\subsection{Selection of resistance}

In an in vitro pharmacokinetic model of infection, the probability of emergence of resistance in $E$. coli was observed especially for low values of $\mathrm{T}>\mathrm{MIC}$ ranging between 10 to $30 \%$ and between 10 to $60 \%$ for $E$. coli and P. aeruginosa, respectively, and increased in relation to time of exposure [57]. The potential for selection for P. aeruginosa resistance with $\mathrm{C} / \mathrm{T}$ was also tested in a hollow-fiber infection model against two $P$. aeruginosa isolates (one wildtype strain with an MIC of $0.5 \mathrm{mg} / \mathrm{L}$ and one clinical isolate with an MIC of $4 \mathrm{mg} / \mathrm{L}$ ) across a wide dose range of 62.5/31.25 - 2000/1000 $\mathrm{mg}$ [67]. Whereas for the wild-type strain none of the dosing regimen selected for resistance, conversely for the clinical isolate, an inverted-Ushaped relationship was found between drug dose and change in bacterial density of resistant subpopulations. The lower $(62.5 / 31.25 \mathrm{mg})$ and the higher $(2000 / 1000 \mathrm{mg})$ dosing regimens prevented the appearance of drug resistance, differently from the intermediate one $(125 / 62.5$ $\mathrm{mg}$ up to $1000 / 500 \mathrm{mg}$ ). These findings supported the idea that a dosing regimen of 2000/1000 $\mathrm{mg}$ of $\mathrm{C} / \mathrm{T}$ may minimize the likelihood of drug-resistance selection for $P$. 
aeruginosa during therapy. Different $\mathrm{C} / \mathrm{T}$ dosing regimens (1000 or $2000 \mathrm{mg}$ ceftolozane and $1000 / 500 \mathrm{mg}$ or $2000 / 1000 \mathrm{mg} \mathrm{C} / \mathrm{T}$ ) were also tested in a hollow-fiber infection model against four strains of E.coli with different $\beta$-lactamase expression (no expression, with an MIC for ceftolozane of $0.25 \mathrm{mg} / \mathrm{L}$; Amp-C, with an MIC for C/T of $1 \mathrm{mg} / \mathrm{L}$; CMY-10, with an $\mathrm{MIC}$ for $\mathrm{C} / \mathrm{T}$ of $4 \mathrm{mg} / \mathrm{L}$ and CTX-M-15, with an MIC for $\mathrm{C} / \mathrm{T}$ of $8 \mathrm{mg} / \mathrm{L}$ ) [68]. All the combinations of $\mathrm{C} / \mathrm{T}$ were bactericidal and completely suppressed the emergence of ceftolozane resistance against three of the four E.coli strains (those with no $\beta$-lactamase expression; with Amp-C and with CMY-10). However, against the CTX-M-15 $\beta$-lactamase strain with a MIC of $8 \mathrm{mg} / \mathrm{L}$, even the $2 \mathrm{~g} / 1 \mathrm{~g} \mathrm{C} / \mathrm{T}$ dosing regimen was unable to completely suppress bacterial growth and to prevent amplification of ceftolozane-resistant populations.

\subsection{Possible alternative dosing regimens}

Similarly to other beta-lactams, given its time-dependent antibacterial activity, it also likely for $\mathrm{C} / \mathrm{T}$ that the application of alternative dosing regimens based on extended-infusion and/or continuous infusion may result in an improvement of the PTA for the treatment of infections due to $P$. aeruginosa with high MICs, above the clinical breakpoint. In a recent Monte Carlo simulation, a previously validated population pharmacokinetic model was used to identify the $\mathrm{C} / \mathrm{T}$ dosing schemes that may optimize the PTA against infections due to P. aeruginosa with a MIC for $\mathrm{C} / \mathrm{T}$ up to $32 \mathrm{mg} / \mathrm{L}$ across different levels of renal function [69]. Among the 512 different scenarios tested, extended infusion of 4-5 h, by achieving higher PTA than shorter or continuous infusion, was shown to probably represent the best administration mode in presence of ARC across infections with MICs ranging between 4 and $32 \mathrm{mg} / \mathrm{L}$, and should merit further investigation.

\subsection{Physical compatibility with other intravenous drugs}


The physical compatibility of $\mathrm{C} / \mathrm{T}$ with other 95 common intravenous drugs was examined by simulating Y-site administration [70]. All the drugs were prepared and reconstituted according to the manufacturers' recommendations and diluted with $0.9 \%$ saline or $5 \%$ dextrose. $\mathrm{C} / \mathrm{T}$ was compatible with $90.5 \%$ of the tested drugs $(86 / 95)$ in both diluents, including metronidazole. It was incompatible with albumin, amphotericin B (both desoxycholate and lipid formulations), caspofungin, cyclosporin, nicardipine, phenitoin and propofol.

\section{Results of clinical studies}

\subsection{Efficacy}

As mentioned before, C/T was approved both by the FDA (December $19^{\text {th }}, 2014$ ) and by EMA (September $18^{\text {th }}, 2015$ ) for the treatment of cIAI and cUTI, based on two phase 3 randomized clinical trials (RCTs), called ASPECT-cIAI, and ASPECT-cUTI, respectively $[71,72]$.

The ASPECT-cIAI study was a multicenter, double-blind, non-inferiority RCT comparing $\mathrm{C} / \mathrm{T}$ plus metronidazole Vs. meropenem for the treatment of complicated intraabdominal infections (cIAI) [71]. Metronidazole was added because of inactivity of C/T against most anaerobes. C/T (1000 $\mathrm{mg}$ of ceftolozane and $500 \mathrm{mg}$ of tazobactam) and metronidazole $(500 \mathrm{mg})$ were administered every $8 \mathrm{~h}$. Meropenem was administered at 1000 mg every $8 \mathrm{~h}$. Both $\mathrm{C} / \mathrm{T}$ and meropenem doses were adjusted according to renal function. Therapy could last from 4 to 10 days, and up to 14 days in case of multiple abscesses, nonappendix-related peritonitis, failure of prior antimicrobial therapy, or hospital-acquired infection. The primary outcome measure was clinical cure, defined as complete resolution of infection or enough improvement requiring no further interventions. Non-inferiority was met both in the microbiological intention-to-treat (MITT) population, including all patients with 
at least 1 baseline pathogen in peritoneal fluid or abscess, and in the microbiological evaluable (ME) population, including all clinically evaluable patients with at least 1 baseline pathogen susceptible to the study drug. In the MITT population, clinical cure rates were $83.0 \%$ in patients receiving ceftolozane/tazobactam plus metronidazole $(323 / 389)$ and $87.3 \%$ in those receiving meropenem (364/417), with a percentage difference of -4.2 (95\% confidence intervals $[\mathrm{CI}]$ from -8.9 to 0.5$)$. In the ME population, clinical cure rates were 94.2\% (259/275) and 94.7\% (304/321) in C/T plus metronidazole- and in meropenem-treated patients, respectively, with a percentage difference of -1.0 (95\% CI from -4.5 to 2.6) [71]. These results are in line with those of a previous multicenter, double-blind, phase II RCT, in which clinical cure of cIAI was reported in $88.7 \%$ (47/53) of ME patients receiving C/T plus metronidazole and in $95.8 \%(23 / 24)$ of $\mathrm{ME}$ patients receiving meropenem (percentage difference $-7.1,95 \%$ CI -30.7 to 16.9$)$ [73].

In a post-hoc analysis of the ASPECT-cIAI trial conducted in ME patients with and without infections due to $P$. aeruginosa, clinical cure rates were similar between $\mathrm{C} / \mathrm{T}$ plus metronidazole and meropenem (100\% [26/26] for C/T vs. 93.1\% [27/19] for meropenem in patients with $P$. aeruginosa infections, and 93.2\% [262/281] for C/T vs. 93.0\% [294/316] for meropenem in patients without $P$. aeruginosa infections) [73]. Of note, as many as $97.1 \%$ of P. aeruginosa isolates in the ASPECT-cIAI study were susceptible to C/T vs. $89.9 \%$ to meropenem [74].

The ASPECT-cUTI study was a multicenter, double-blind, double-dummy, noninferiority $\mathrm{RCT}$ comparing $\mathrm{C} / \mathrm{T}$ vs. levofloxacin for the treatment of complicated urinarytract infections (cUTI), including pyelonephritis [72]. $\mathrm{C} / \mathrm{T}$ and levofloxacin were administered at $1500 \mathrm{mg}$ every $8 \mathrm{~h}(1000 \mathrm{mg}$ of ceftolozane and $500 \mathrm{mg}$ of tazobactam) and at $750 \mathrm{mg}$ once daily, respectively. Both $\mathrm{C} / \mathrm{T}$ and levofloxacin were administered for seven days. Doses were adjusted according to renal function. The primary outcome measure was 
composite cure, defined as clinical cure plus microbiological eradication of all baseline uropathogens. Superiority was met both in the microbiological modified intention-to-treat (mMITT) population, including all patients with growth of one or two uropathogens of at least $10^{5}$ colony-forming units per $\mathrm{mL}$ in urine culture, and in the per-protocol population, including all mMITT patients who adhered to the treatment protocol and had a clinical assessment and interpretable urine culture at the test of cure. In the MITT population, composite cure rates were $76.9 \%$ in patients receiving $\mathrm{C} / \mathrm{T}(306 / 398)$ and $68.4 \%$ in those receiving levofloxacin (275/402), with a percentage difference of 8.5 (95\% Cl from 2.3 to 14.6). In the per-protocol population, composite cure rates were $83.3 \%(284 / 341)$ and $75.4 \%$ (266/353) in C/T- and in levofloxacin-treated patients, respectively, with a percentage difference of 8.0 (95\% CI from 2.0 to 14.0$)$. Of note, microbiological eradication in patients with $P$. aeruginosa at baseline was $6 / 7(85.7 \%)$ and $7 / 12(58.3 \%)$ in patients treated with $\mathrm{C} / \mathrm{T}$ and levofloxacin, respectively (percentage difference $27.4,95 \%$ CI from -15.9 to 56.3) [72].

Since as many as $216 / 800$ patients in the mMITT population had a baseline uropathogen resistant to levofloxacin (26.5\%), a post-hoc analysis was conducted to compare composite cure rates between $\mathrm{C} / \mathrm{T}$ and levofloxacin in two different subgroups: (1) patients in the mMITT population with levofloxacin-resistant pathogens; (2) patients in the mMITT population with levofloxacin-susceptible pathogens [75]. In patients with levofloxacinresistant pathogens, composite cure rates were $60.0 \%$ in patients receiving $C / T(60 / 100)$ and $39.3 \%$ in those receiving levofloxacin (44/112), with a percentage difference of 20.7 (95\% CI from 7.2 to 33.2). In patients with levofloxacin-susceptible pathogens, composite cure rates were $84.9 \%(231 / 272)$ and $81.1 \%(210 / 259)$ in C/T- and in levofloxacin-treated patients, respectively, with a percentage difference of 3.8 (95\% CI from -2.6 to 10.3) [75].

In a pooled post-hoc analysis including ME patients from both ASPECT-cIAI and ASPECT-cUTI who had an ESBL-producing member of the Enterobacteriaceae in their 
baseline cultures $(150 / 1346,11.1 \%)$, clinical cure rates were $97.4 \%$ for $\mathrm{C} / \mathrm{T}(76 / 78), 82.6 \%$ for levofloxacin, and $88.5 \%$ for meropenem (23/26) [76]. In another post-hoc analysis including data from both ASPECT-cIAI and ASPECT-cUTI, response rates (i.e., clinical cure or composite cure according to the primary endpoint of the two different trials) were compared between $\mathrm{C} / \mathrm{T}$ and comparators in patients with diabetes [77]. In diabetic cIAI patients, clinical cure rates were $71.9 \%$ in those receiving $\mathrm{C} / \mathrm{T}$ plus metronidazole $(23 / 32)$ and $78.8 \%$ in those receiving levofloxacin $(26 / 33)$, with a percentage difference of $-6.9(95 \%$ CI from -27.9 to $14.4 \%$. In diabetic cUTI patients, composite cure rates were $64.2 \%(43 / 67)$ and $60.6 \%(40 / 66)$ in $\mathrm{C} / \mathrm{T}$ - and in levofloxacin-treated patients, respectively, with a percentage difference of 3.6 (95\% CI from -12.8 to 19.8$)$ [77]. Finally, in a pre-defined exploratory subgroup analysis including only those patients from MITT population in cIAI and mMITT population in cUTI who had moderate renal insufficiency (defined as CLCr of $30-50 \mathrm{~mL} / \mathrm{min}$ ), response rates were $72.7 \%$ for $\mathrm{C} / \mathrm{T}$ and $71.4 \%$ for meropenem in cIAI, and $87 \%$ for $\mathrm{C} / \mathrm{T}$ and $80 \%$ for levofloxacin in cUTI [78].

A third RCT, ASPECT-NP, comparing C/T vs. meropenem for treating hospitalacquired bacterial pneumonia (HABP) or ventilator-associated bacterial pneumonia (VABP) in adults is currently recruiting participants (NCT02070757). A detailed summary of efficacy data from ASPECT-cIAI and ASPECT-cUTI trials is available in Table 3.

\subsection{Safety}

$\mathrm{C} / \mathrm{T}$ is generally well-tolerated, with the most frequent adverse events (AEs) being those associated with any other cephalosporin, such as nausea, vomiting, and diarrhea [71-73, 7778]. In the two phase III (ASPECT-UTI and ASPECT-cIAI) and in the one phase II randomized clinical trials (RCTs) involving ceftolozane/tazobactam, a similar frequency of AEs was observed in patients treated with ceftolozane/tazobactam and in those treated with 
comparators [71-73]. Overall, AEs were 438/1097 (39.9\%) in C/T-treated patients and 415/1071 (38.7\%) in those receiving other agents (levofloxacin for ASPECT-UTI and meropenem for the other two studies). Serious AEs were 68/1097 (6.2\%) and 56/1071 (5.2\%), respectively. In C/T-treated patients, only 3 serious AEs were deemed as drugrelated, all being Clostridium difficile infection (CDI). No drug-related deaths were reported. The full list of AEs observed in RCTs is reported in table 4.

According to a pre-defined exploratory analysis and a post-hoc analysis of data from both ASPECT-cIAI and ASPECT-cUTI, C/T was also well-tolerated in patients with moderate renal insufficiency or diabetes, respectively $[77,78]$. With regard to moderate renal insufficiency, 41/70 patients receiving $\mathrm{C} / \mathrm{T}$ experienced AEs vs. $35 / 54$ patients receiving comparators (58.6\% vs. 64.8\%, respectively) [78]. Serious AEs were more frequent in moderate compared with mild/no renal insufficiency patients (16.9\% vs $4.5 \%)$. Five patients with cIAI and moderate renal insufficiency died, but all deaths were considered unrelated to the study drug [77]. With regard to diabetes, patients with the disease were more likely to have AEs (49.0\% vs $37.3 \%$ ) and serious AEs (10.6\% vs $4.6 \%)$ than those without, although the proportions of treatment-related AEs were not different between the two groups $(8.2 \% \mathrm{vs}$ $10.1 \%)[77]$.

Regarding post-marketing safety evaluation, seven cases of medication error were reported to the Food and Drug Administration (FDA) [79]. All cases were due to a wrong preparation of $\mathrm{C} / \mathrm{T}$ in the pharmacy, leading to the administration of $50 \%$ more than was prescribed. However, no AEs were reported in all 7 cases [79]. In a multicenter, retrospective study of 35 patients infected with carbapenem-resistant Pseudomonas aeruginosa and treated with $\mathrm{C} / \mathrm{T}$, dosage and length of therapy ranged from 375 to $3000 \mathrm{mg}$ every $8 \mathrm{~h}$ and from 5 to 27 days, respectively [80]. Nine out of 20 patients with $\mathrm{CrCL}>50 \mathrm{~mL} / \mathrm{min}$ were given 3000 mg of $\mathrm{C} / \mathrm{T}$ every $8 \mathrm{~h}$. Two AEs were attributed to $\mathrm{C} / \mathrm{T}$ : (i) self-limited diarrhea with a 
negative Clostridium difficile molecular test; (ii) peripheral eosinophilia with eosinophiluria, possibly due to interstitial nephritis. In the latter case, the eosinophil count normalized after $\mathrm{C} / \mathrm{T}$ was stopped, and no renal damage was later found.

In summary, C/T has shown good tolerability, similar to those of other cephalosporins (including a similar incidence of CDI). Higher dosages up to $3000 \mathrm{mg}$ every 8 hours and longer courses of treatment seem not to unfavorably affect tolerability.

\section{Conclusion}

In conclusion, $\mathrm{C} / \mathrm{T}$ is the first cephalosporin active against ESBL-producing Gram negative rod, which finds its place in therapy in severe infections due to these pathogens, especially when a carbapenem-sparing approach is desirable. The drug is safe and has a favorable PK and PD profile. The drug's activity against many Pseudomonas strains that are resistant to other beta-lactams (including carbapenems) is very promising, making $\mathrm{C} / \mathrm{T}$ first, although not always approved choice for these infections. In some cases of MDR-Pseudomonas infections due to $\mathrm{C} / \mathrm{T}$ susceptible strains, that are outside the setting of the approved indications, offlabel use is probably mandatory.

\section{Expert Commentary}

$\mathrm{C} / \mathrm{T}$ is indicated in cIAI and cUTI. In addition, the results of the Phase-3 ASPECT-NP trial for the treatment of VABP and HABP (NCT02070757) might shortly allow the inclusion of severe respiratory infections within the approved indications. We agree that at this point the spectrum of indications will be quite large, although severe infections, like bacteremias, are not among the indications and the drug could not be used for this indication, unless bacteremia is associated with an abdominal, pulmonary or urinary source. Unfortunately, so far, the regulatory agencies did not allow the possibility to use $\mathrm{C} / \mathrm{T}$ in other severe infections, due by susceptible pathogens, in districts where the drug may reach active concentrations and 
in patients with no or limited alternatives (for example, for treating MDR P. aeruginosa osteomyelitis). This is actually the main point, i.e. the fact that the drug was not studied and therefore was not approved according to a pathogen instead of site-oriented approach. The approved indications are either restrictive or quite large. Indeed, what is of interest for clinicians is not the possibility to use a drug like $\mathrm{C} / \mathrm{T}$ for indications for which several less expensive antibiotics might be available, but rather to use it in unmet clinical needs, based on the pathogen likely involved, according to a targeted, colonization-based or epidemiologicalbased approach. The place-in-therapy of $\mathrm{C} / \mathrm{T}$ in our opinion is not universal in IAIs, UTIs or lung infections, but rather (i) in any infection (in sites where the drug goes readily), likely sustained by an ESBL-producing Gram-negative rod in centers where a carbapenem-sparing approach is desirable and (ii) in infections sustained by MDR-Pseudomonas which remains susceptible to $\mathrm{C} / \mathrm{T}$.

7.1 $\mathrm{C} / \mathrm{T}$ in a carbapenem-sparing approach. $\mathrm{C} / \mathrm{T}$ has been proposed as a potential alternative to carbapenems for the treatment of ESBL infections, according to a carbapenemsparing strategy aimed at recuperating carbapenem activity. Indeed, carbapenem overutilization stimulates the selection and diffusion of carbapenemases, which might further prejudicate our ability to treat infections due to MDR Enterobacteriaceae [9] and the reduction in carbapenem use has been associated with a decrease in infections due to CPE [81]. We believe that in centers where ESBL-producing Gram-negative rods are endemic, a carbapenem-sparing strategy in first-line and de-escalation therapy, might be proposed in presence of even sporadic infections due to $\mathrm{CPE}$, without waiting for $\mathrm{CPE}$ to become endemic. Whether or not a carbapenem-sparing strategy might be obtained by using piperacillin-tazobactam (less expensive than $\mathrm{C} / \mathrm{T}$ ) for ESBL-producers, is a matter of debate [82]. Some data support a possible similar efficacy to carbapenems, provided piperacillintazobactam is used at the maximum tolerated dose (4.5 g q6), while others studies have 
favored carbapenems, especially in critically-ill patients [9, 83-86]. In our opinion the situation is multifaceted and might be related to piperacillin-tazobactam MICs, site of infection and patient-related factors, including severity of the clinical presentation, although meropenem choice is probably based on more solid data. For a definite answer we are waiting for the results of the MERINO study, which is comparing piperacillin/tazobactam vs. meropenem for treating bloodstream infections due to ceftriaxone-resistant $E$. coli and $K$. pneumoniae (NCT02176122). In any case, it is worth noting that the use of $\mathrm{C} / \mathrm{T}$ as a carbapenem-sparing agent would be in line with its high in vitro activity against ESBLproducers [29, 30], as well as with some recent decision-analytic Monte Carlo models indicating $\mathrm{C} / \mathrm{T}$ to be possibly more cost-effective than piperacillin/tazobactam for cIAI and cUTI $[87,88]$. Cost issues exist, of course, although in other disciplines, like oncology, cost considerations have not prevented the use of terribly expensive drugs [89, 90].

7.2 C/T in MDR-P. aeruginosa. In many countries, approximately $25-50 \%$ of $P$. aeruginosa isolates are resistant to carbapenems, and up to $10-50 \%$ of strains can be classified as MDR $[4,91]$. This poses some difficulties in defining the best therapeutic approach in patients at risk for Pseudomonas (for example, patients with hematological malignancies colonized or with history of Pseudomonas infections), since the risk of resistance to all the commonly used antipseudomonal agents (fluoroquinolones, aminoglycosides, cephalosporins, and carbapenems) is certainly non-negligible. In this worrisome scenario, $\mathrm{C} / \mathrm{T}$ might remain active, in view of its ability to elude multiple resistance mechanisms, including efflux pumps, reduced uptake through porin channels, and modification of penicillin-binding proteins [23]. The main problem is nonetheless that carbapenem-resistant $P$. aeruginosa can also cause infections other than cIAI and cUTI, for example pneumonia or BSI. Against this background, it might have been very helpful for patients and clinicians if both MSD and the regulatory agencies would have been more far-sighted, by conducting (or recommending to 
conduct) phase II studies for this specifying indication. What scientific societies might do, right now, is to try to collect as much information as possible about the efficacy of C/T offlabel use in Pseudomonas infections, in order to increase the body of evidence and obtain a secondary indication. For the time being, published case series and case reports describing the real life use of $\mathrm{C} / \mathrm{T}$ for off-label indications are made up almost exclusively of patients with infections caused by this organism (around one hundred patients cumulatively). The largest series included 35 patients with various infections (mostly pneumonia, 18/35, 51\%) due to carbapenem-resistant $P$. aeruginosa [80]. Clinical success, defined as a composite outcome of in-hospital survival and resolution of signs and symptoms of infection according to the treating physicians, was reported in $74 \%$ of patients $(26 / 35)$. Of note, there was a wide variation of $\mathrm{C} / \mathrm{T}$ dosing even for similar types of infections and renal function. Furthermore, it is also worth noting that treatment was unsuccessful in all cases of infections due to $P$. aeruginosa with $\mathrm{C} / \mathrm{T} \mathrm{MIC}>4 \mathrm{mg} / \mathrm{L}$ [80]. In another series of 12 patients with a severe infections due to MDR P. aeruginosa (again, mostly pneumonia, 6/12, 50\%) who received $\mathrm{C} / \mathrm{T}$ as salvage therapy after inappropriate or suboptimal initial treatment, and of whom 10/12 had septic shock (83\%), the observed survival was $75 \%(9 / 12)$ [92]. In another recent study, $\mathrm{C} / \mathrm{T}$ was successful in treating 15/21 patients with various MDR $P$. aeruginosa infections (71\%), although it should be noted that resistance to $\mathrm{C} / \mathrm{T}$ conferred by de novo mutations occurred in $14 \%$ of cases (3/21) [43]. Regarding case reports and small case series, they also mainly reported on the successful off-label use of $\mathrm{C} / \mathrm{T}$ for treating infections due MDR $P$. aeruginosa (mostly pneumonia, bloodstream infections, osteomyelitis, and acute pulmonary exacerbation of cystic fibrosis) [54, 93-112]. More reports will come in the near future, that remain critical to enrich our knowledge about the effectiveness of $\mathrm{C} / \mathrm{T}$ for all these indications. Studies to collect information about C/T in Pseudomonas infections are ongoing, with some preliminary results presented in international conferences $[113,114]$. 
7.3 In vitro susceptibility. We believe that $\mathrm{C} / \mathrm{T}$ should be routinely and automatically tested against every Gram-negative rod isolated from any site, and, especially, against Pseudomonas. Every delay in understanding whether or not a given Pseudomonas MDR strain is actually susceptible to $\mathrm{C} / \mathrm{T}$ is deleterious for the patient and unacceptable for clinicians.

\section{Five-year view}

Unless decisions are taken by the regulatory agencies and/or more data are provided by sponsored or spontaneous studies, in the next 5 years we will probably observe an increasing use of $\mathrm{C} / \mathrm{T}$ in unapproved indications such as bacteremia, neutropenic infections, skin infections, osteomyelitis, prosthetic infections, and pulmonary exacerbations of cystic fibrosis caused by (or suspected to be caused by) MDR $P$. aeruginosa, reflecting the important urgent and unmet clinical need to find an active agent against this pathogen.

\section{Key Issues}

- $\mathrm{C} / \mathrm{T}$ is the combination of a novel cephalosporin, structurally similar to ceftazidime, with a well-known $\beta$-lactamase inhibitor

- $\mathrm{C} / \mathrm{T}$ has shown activity against MDR $P$. aeruginosa and ESBL-producing Enterobacteriaceae, and has been recently approved for the treatment of cIAI and cUTI, including pyelonephritis, by the U.S. Food and Drug Administration and the European Medicines Agency

- The approval of $\mathrm{C} / \mathrm{T}$ for the treatment of cIAI and cUTI is based on two phase 3 noninferiority RCTs, ASPECT-cIAI, and ASPECT-cUTI.

- Observational studies reporting the use of $\mathrm{C} / \mathrm{T}$ are made up almost exclusively of case series and case reports of infections due to MDR $P$. aeruginosa, reflecting the urge for an active agent against this organism. 
- $\mathrm{C} / \mathrm{T}$ is a promising carbapenem-sparing agent that should be used thoughtfully, taking into account the local microbiological epidemiology and its spectrum of activity.

- Pending broader experience with gradient and disk diffusion tests, and implementation of the drug in validated panels of semiautomated systems, current evidence would suggest the use of broth microdilution for $\mathrm{C} / \mathrm{T}$ susceptibility testing.

- Doubling of the currently approved dose may be appropriate in patients with normal renal function in order to achieve PTA $>90 \%$ in ELF against $P$. aeruginosa with a MIC up to $8 \mathrm{mg} / \mathrm{L}$ for optimal treatment of hospital-acquired and ventilator-associated pneumonia. 


\section{Funding}

This work, including travel and meeting expenses, was funded by an unrestricted grant by MSD Italia Srl. The sponsor had no role in selecting the participants, reviewing the literature, defining recommendations, drafting or reviewing the paper, or in the decision to submit the manuscript for publication. All views expressed are solely those of the authors.

\section{Declaration of interest}

DR Giacobbe received an unconditioned grant from MSD Italy. M Bassetti participated in advisory boards and/or received speaker honoraria from Achaogen, Angelini, Astellas, AstraZeneca, Bayer, Basilea, Cidara, Gilead, Menarini, MSD, Paratek, Pfizer, The Medicine Company, Tetraphase and Vifor. F Giuseppe De Rosa received speaker fees and participated in advisory boards for MSD. V Del Bono received speaker fees from Pfizer, MSD, Basilea, Astellas, Gilead and Sanofi. PA Grossi acted as consultant and member of speakers bureau for MSD, G'lead, BD, Ange ini, Paratek, and Novartis. F Menichetti participated in advisory boards and/or received speaker honoraria from Pfizer, Gilead, Angelini, and MSD. F Pea participated in speaker bureau for Angelini, Basilea Pharmaceut'ca, Gilead, Hikma, Merck Sharp \& Dohme, Nordic Pharma, Pfizer, and Sanofi Aventis, and in advisory board for Angelini, Basilea Pharmaceutica, Gilead, Merck Sharp \& Dohme, Nordic Pharma, and Pfizer. GM Rossolini has served as a consultant to and/or received congress lecture fees and/or research grants and/or travel grants from Accelerate, Achaogen, Alifax, Angelini, Arrow, AstraZeneca, Basilea, Beckman Cou ter, BectonDickinson, bioMérieux, Biotest, Cepheid, Checkpoints, Elitech, Estor, Liofilchem, Merck, Nordic Pharma, Novartis, Pfizer, Rempex, Roche, Seegene, ThermoFisher, Zambon. M Tumbarello received speaker fees and participated in advisory boards for MSD 
PL Viale acted as consultant to Pfizer, Cepheid and Merck Sharp \& Dohme, received research grants from Gilead Sciences and Pfizer, honoraria for lectures from Gilead Sciences, Merck Sharp \& Dohme and Pfizer, and travel grants from Merck Sharp \& Dohme, Pfizer and Gilead Sciences. C Viscoli reports personal fees from IViGD Int, Gi ead, Forrest ta ia, Angelini and Pfizer. The authors have no other relevant affiliations or financial involvement with any organization or entity with a financial interest in or financial conflict with the subject matter or materials discussed in the manuscript apart from those disclosed. Peer reviewers on this manuscript have no relevant financial or other relationships to disclose. 


\section{References}

\section{Reference annotations}

\section{* Of interest}

\section{** Of considerable interest}

1. Pitout JD, Laupland KB. Extended-spectrum b-lactamase-producing Enterobacteriaceae: an emerging publichealth concern. Lancet Infect Dis. 2008; 8:159-66.

2. Paterson DL, Hujer KM, Hujer AM, et al. International Klebsiella Study Group. Extended-spectrum betalactamases in Klebsiella pneumoniae bloodstream isolates from seven countries: dominance and widespread prevalence of SHV- and CTX-M-type beta-lactamases. Antimicrob Agents Chemother. 2003; 47:3554-60.

3. Tumbarello M, Repetto E, Trecarichi EM, et al. Multidrug-resistant Pseudomonas aeruginosa bloodstream infections: risk factors and mortality. Epidemiol Infect. 2011; 139:1740-9.

4. Centers for Disease Control and Prevention. Antibiotic resistance threats in the United States. Centers for Disease Control and Prevention 2016, Atlanta, GA: http://www.cdc.gov/drugresistance/pdf/ar-threats-2013-508.pdf. Last accessed October 30, 2017.

5. Bassetti M, Poulakou G, Ruppe E, et al, Antimicrobial resistance in the next 30 years, humankind, bugs and drugs: a visionary approach. Intensive Care Med. 2017. doi: 10.1007/s00134-017-4878-x.

* An interesting review giving a prospective overview for the next 30 years in the field of antimicrobial resistance

6. Zilberberg MD, Shorr AF, Micek ST, et al. Multi-drug resistance, inappropriate initial antibiotic therapy and mortality in Gram-negative severe sepsis and septic shock: a retrospective cohort study. Crit Care. 2014; 18:596.

7. Marston HD, Dixon DM, Knisely JM, et al. Antimicrobial resistance. JAMA. 2016; 316:1193-204.

8. Giacobbe DR, Del Bono V, Trecarichi EM, et al. Risk factors for bloodstream infections due to colistin-resistant KPC-producing Klebsiella pneumoniae: results from a multicenter case-control-control study. Clin Microbiol Infect. 2015; 21:1106.e1-8. 
9. Tamma PD, Rodriguez-Bano J. The Use of Noncarbapenem $\beta$-Lactams for the Treatment of Extended-Spectrum $\beta$-Lactamase Infections. Clin Infect Dis. 2017; 64:972-80.

* A comprehensive review on the possible use of noncarbapenem $\beta$-Lactams for treating ESBL-producing

\section{Enterobacteriaceae infections}

10. Wright H, Bonomo RA, Paterson DL. New agents for the treatment of infections with Gram-negative bacteria: restoring the miracle or false dawn? Clin Microbiol Infect. 2017; 23:704-12.

11. U.S. Food and Drug Administration. Zerbaxa ${ }^{\circledR}$. Full prescribing information. https://www.accessdata.fda.gov/drugsatfda_docs/label/2014/206829lbl.pdf. Last accessed October 30, 2017.

12. European Medicines Agency. Zerbaxa ${ }^{\circledR}$. Annex I. Summary of product characteristics http://www.ema.europa.eu/docs/en_GB/document_library/EPAR__Product_Information/human/003772/WC500194595.pdf. Last accessed October 30, 2017

13. Moya B, Zamorano L, Juan C, et al. Affinity of the new cephalosporin CXA-101 to penicillin-binding proteins of Pseudomonas aeruginosa. Antimicrob Agents Chemother. 2010; 54:3933-7.

14. Murano K, Yamanaka T, Toda A, et al. Structural requirements for the stability of novel cephalosporins to AmpC beta-lactamase based on 3D-structure. Bioorg Med Chem. 2008; 16:2261-75.

15. Takeda S, Ishii Y, Hatano K, et al. Stability of FR264205 against AmpC beta-lactamase of Pseudomonas aeruginosa. Int J Antimicrob Agents. 2007; 30:443-5.

16. Moyá B, Beceiro A, Cabot G, et al. Pan- $\beta$-lactam resistance development in Pseudomonas aeruginosa clinical strains: molecular mechanisms, penicillin-binding protein profiles, and binding affinities. Antimicrob Agents Chemother. 2012; 56:4771-8.

17. Castanheira M, Mills JC, Farrell DJ, et al. Mutation-driven $\beta$-lactam resistance mechanisms among contemporary ceftazidime-nonsusceptible Pseudomonas aeruginosa isolates from U.S. hospitals. Antimicrob Agents Chemother. 2014; 58:6844-50.

18. Moyá B, Zamorano L, Juan C, et al. Activity of a new cephalosporin, CXA-101 (FR264205), against beta-lactamresistant Pseudomonas aeruginosa mutants selected in vitro and after antipseudomonal treatment of intensive care unit patients. Antimicrob Agents Chemother. 2010; 54:1213-7. 
19. Riera $\mathrm{E}, \mathrm{Macià} \mathrm{MD}$, Mena $\mathrm{A}$, et al. Anti-biofilm and resistance suppression activities of CXA-101 against chronic respiratory infection phenotypes of Pseudomonas aeruginosa strain PAO1. J Antimicrob Chemother. 2010; 65:1399-404.

20. Velez Perez AL, Schmidt-Malan SM, Kohner PC, et al. In vitro activity of ceftolozane/tazobactam against clinical isolates of Pseudomonas aeruginosa in the planktonic and biofilm states. Diagn Microbiol Infect Dis. 2016; 85:356-9.

21. Livermore DM, Mushtaq S, Ge Y. Chequerboard titration of cephalosporin CXA-101 (FR264205) and tazobactam versus beta-lactamase producing Enterobacteriaceae. J. Antimicrob. Chemother. 2010; 65:1972-4.

22. Sader HS, Rhomberg PR, Farrell DJ, et al. Antimicrobial activity of CXA-101, a novel cephalosporin tested in combination with tazobactam against Enterobacteriaceae, Pseudomonas aeruginosa, and Bacteroides fragilis strains having various resistance phenotypes. Antimicrob Agents Chemother. 2011; 55:2390-4.

23. Zhanel GG, Chung P, Adam H, et al. Ceftolozane/tazobactam: a novel cephalosporin/ $\beta$-lactamase inhibitor combination with activity against multidrug-resistant gram-negative bacilli. Drugs. 2014; 74:31-51.

24. Mazer DM, Young C, Kalikin LM, et al. In vitro activity of ceftolozane-tazobactam and other antimicrobial agents against Burkholderia cepacia complex and Burkholderia gladioli. Antimicrob Agents Chemother. 2017; doi: 10.1128/AAC.00766-17.

25. Livermore DM, Mushtaq S, Meunier D, et al. Activity of ceftolozane/tazobactam against surveillance and 'problem' Enterobacteriaceae, Pseudomonas aeruginosa and non-fermenters from the British Isles. J Antimicrob Chemother. 2017; 72:2278-89.

26. Armstrong ES, Farrell DJ, Palchak M, et al. In vitro activity of ceftolozane-tazobactam against anaerobic organisms identified during the ASPECT-cIAI Study. Antimicrob Agents Chemother 2015; 60:666-8.

27. Gonzalez MD, Wallace MA, Hink T, et al. Ceftolozane-tazobactam activity against phylogenetically diverse Clostridium difficile strains. Antimicrob Agents Chemother. 2015; 59:7084-5.

28. Shortridge D, Castanheira M, Pfaller MA, et al. Ceftolozane-Tazobactam Activity against Pseudomonas aeruginosa Clinical Isolates from U.S. Hospitals: Report from the PACTS Antimicrobial Surveillance Program, 2012 to 2015. Antimicrob Agents Chemother. 2017; doi: 10.1128/AAC.00465-17.

29. Pfaller MA, Bassetti M, Duncan LR, et al. Ceftolozane/tazobactam activity against drug-resistant Enterobacteriaceae and Pseudomonas aeruginosa causing urinary tract and intraabdominal infections in Europe: report from an antimicrobial surveillance programme (2012-15). J Antimicrob Chemother. 2017; 72:1386-95. 


\section{* Prospective surveillance of ceftolozane/tazobactam activity against 6553 Gram-negative organisms}

30. Pfaller MA, Shortridge D, Sader HS, et al. Ceftolozane-tazobactam activity against drug-resistant Enterobacteriaceae and Pseudomonas aeruginosa causing healthcare-associated infections in Latin America: report from an antimicrobial surveillance program (2013-2015). Braz J Infect Dis. 2017; doi: 10.1016/j.bjid.2017.06.008.

31. Pfaller MA, Shortridge D, Sader HS, et al. Ceftolozane-tazobactam activity against drug-resistant Enterobacteriaceae and Pseudomonas aeruginosa causing healthcare-associated infections in Australia and New Zealand: Report from an Antimicrobial Surveillance Program (2013-2015). J Glob Antimicrob Resist. 2017; 10:186-94.

32. Seifert H, Körber-Irrgang B, Kresken M. In-vitro activity of ceftolozane/tazobactam against Pseudomonas aeruginosa and enterobacteriaceae isolates recovered from hospitalized patients in Germany. Int J Antimicrob Agents. 2017; doi: 10.1016/j.ijantimicag.2017.06.024.

33. Giani T, Arena F, Pollini S, et al. Italian nationwide survey on Pseudomonas aeruginosa from invasive infections: activity of ceftolozane/tazobactam and comparators, and molecular epidemiology of carbapenemase producers. J Antimicrob Chemother. 2017; doi:10.1093/jac/dkx453.

34. Grupper M, Sutherland C, Nicolau DP. Multicenter Evaluation of Ceftazidime-Avibactam and CeftolozaneTazobactam Inhibitory Activity against Meropenem-Nonsusceptible Pseudomonas aeruginosa from Blood, Respiratory Tract, and Wounds. Antimicrob Agents Chemother. 2017; doi: 10.1128/AAC.00875-17.

35. Zamorano L, Juan C, Fernández-Olmos A, et al. Activity of the new cephalosporin CXA-101 (FR264205) against Pseudomonas aeruginosa isolates from chronically-infected cystic fibrosis patients. Clin Microbiol Infect. 2010; $16: 1482-7$.

36. Kuti JL, Pettit RS, Neu N, et al. Microbiological activity of ceftolozane/tazobactam, ceftazidime, meropenem, and piperacillin/tazobactam against Pseudomonas aeruginosa isolated from children with cystic fibrosis. Diagn Microbiol Infect Dis. 2015; 83:53-5.

37. Grohs P, Taieb G, Morand P, et al. n Vitro Activity of Ceftolozane-Tazobactam against Multidrug-Resistant Nonfermenting Gram-Negative Bacilli Isolated from Patients with Cystic Fibrosis. Antimicrob Agents Chemother. 2017; doi: 10.1128/AAC.02688-16.

38. Shortridge D, Pfaller MA, Castanheira M, et al. Antimicrobial Activity of Ceftolozane-Tazobactam Tested Against Enterobacteriaceae and Pseudomonas aeruginosa with Various Resistance Patterns Isolated in U.S. Hospitals 
(2013-2016) as Part of the Surveillance Program: Program to Assess Ceftolozane-Tazobactam Susceptibility. Microb Drug Resist. 2017; doi: 10.1089/mdr.2017.0266.

39. Fraile-Ribot PA, Mulet X, Cabot G, et al. In Vivo Emergence of Resistance to Novel Cephalosporin- $\beta$-Lactamase Inhibitor Combinations through the Duplication of Amino Acid D149 from OXA-2 $\beta$-Lactamase (OXA-539) in Sequence Type 235 Pseudomonas aeruginosa. Antimicrob Agents Chemother. 2017; doi: 10.1128/AAC.0111717.

40. Schaumburg F, Bletz S, Mellmann A, et al. Susceptibility of MDR Pseudomonas aeruginosa to ceftolozane/tazobactam and comparison of different susceptibility testing methods. J Antimicrob Chemother. 2017; doi: 10.1093/jac/dkx253.

41. Cabot G, Bruchmann S, Mulet X, et al. Pseudomonas aeruginosa ceftolozane-tazobactam resistance development requires multiple mutations leading to overexpression and structural modification of AmpC. Antimicrob Agents Chemother. 2014; 58:3091-9.

42. Berrazeg M, Jeannot K, Ntsogo Enguéné VY, et al. Mutations in $\beta$-Lactamase AmpC Increase Resistance of Pseudomonas aeruginosa Isolates to Antipseudomonal Cephalosporins. Antimicrob Agents Chemother 2015; 59: 6248-55.

43. Haidar G, Philips NJ, Shields RK, et al. Ceftolozane-Tazobactam for the Treatment of Multidrug-Resistant Pseudomonas aeruginosa Infections: Clinical Effectiveness and Evolution of Resistance. Clin Infect Dis. 2017; $65: 110-20$.

44. MacVane SH, Pandey R, Steed LL, et al. Emergence of Ceftolozane-Tazobactam Resistant Pseudomonas aeruginosa During Treatment is Mediated by a Single AmpC Structural Mutation. Antimicrob Agents Chemother. 2017; doi: 10.1128/AAC.01183-17.

45. Clinical and Laboratory Standards Institute. M100-S27. Performance standards for antimicrobial susceptibility testing: 27th informational supplement. Clinical and Laboratory Standards Institute 2017, Wayne, PA.

46. EUCAST. Breakpoint tables for interpretation of MICs and zone diameters. Version 7.1, 2017. http://www.eucast.org/clinical_breakpoints/. Last accessed October 30, 2017.

47. Flynt LK, Veve MP, Samuel LP, et al. Comparison of Etest to broth microdilution for testing of susceptibility of Pseudomonas aeruginosa to ceftolozane-tazobactam. J Clin Microbiol. 2017; 55:334-5.

48. Cho JC, Fiorenza MA, Estrada SJ. Ceftolozane/Tazobactam: A Novel Cephalosporin/beta-Lactamase Inhibitor Combination. Pharmacotherapy. 2015; 35:701-15. 
49. Sucher AJ, Chahine EB, Cogan P, et al. Ceftolozane/Tazobactam: A New Cephalosporin and beta-Lactamase Inhibitor Combination. Ann Pharmacother. 2015; 49:1046-56.

50. Wise R, Logan M, Cooper M, et al. Pharmacokinetics and tissue penetration of tazobactam administered alone and with piperacillin. Antimicrob Agents Chemother. 1991; 35:1081-4.

51. Wooley M, Miller B, Krishna G, et al. Impact of renal function on the pharmacokinetics and safety of ceftolozanetazobactam. Antimicrob Agents Chemother. 2014; 58:2249-55.

52. Liscio JL, Mahoney MV, Hirsch EB. Ceftolozane/tazobactam and ceftazidime/avibactam: two novel betalactam/beta-lactamase inhibitor combination agents for the treatment of resistant Gram-negative bacterial infections. Int J Antimicrob Agents. 2015; 46:266-71.

53. Monogue ML, Stainton SM, Baummer-Carr A, et al. Pharmacokinetics and Tissue Penetration of Ceftolozane/Tazobactam in Diabetic Patients with Lower Limb Infections and Healthy Adult Volunteers. Antimicrob Agents Chemother. 2017; doi: 10.1128/AAC.01449-17.

54. Bremmer DN, Nicolau DP, Burcham P, et al. Ceftolozane/Tazobactam Pharmacokinetics in a Critically Ill Adult Receiving Continuous Renal Replacement Therapy. Pharmacotherapy. 2016; 36:e30-e33.

55. Kuti JL, Ghazi IM, Quintiliani R Jr, et al. Treatment of multidrug-resistant Pseudomonas aeruginosa with ceftolozane/tazobactam in a critically ill patient receiving continuous venovenous haemodiafiltration. Int $\mathrm{J}$ Antimicrob Agents. 2016; 48;342-3.

56. Craig WA, Andes DR. In vivo activities of ceftolozane, a new cephalosporin, with and without tazobactam against Pseudomonas aeruginosa and Enterobacteriaceae, including strains with extended-spectrum beta-lactamases, in the thighs of neutropenic mice. Antimicrob Agents Chemother. 2013; 57:1577-82.

57. MacGowan AP, Noel AR, Tomaselli SG, et al. Pharmacodynamics of Ceftolozane plus Tazobactam Studied in an In Vitro Pharmacokinetic Model of Infection. Antimicrob Agents Chemother. 2015; 60:515-21.

58. VanScoy B, Mendes RE, Nicasio AM et al. Pharmacokinetics-pharmacodynamics of tazobactam in combination with ceftolozane in an in vitro infection model. Antimicrob Agents Chemother. 2013; 57:2809-14.

59. VanScoy B, Mendes RE, McCauley J et al. Pharmacological basis of beta-lactamase inhibitor therapeutics: tazobactam in combination with Ceftolozane. Antimicrob Agents Chemother. 2013; 57:5924-30.

60. Soon RL, Lenhard JR, Bulman ZP et al. Combinatorial Pharmacodynamics of Ceftolozane-Tazobactam against Genotypically Defined beta-Lactamase-Producing Escherichia coli: Insights into the 
Pharmacokinetics/Pharmacodynamics of beta-Lactam-beta-Lactamase Inhibitor Combinations. Antimicrob Agents Chemother. 2016; 60:1967-73.

61. Melchers MJ, Mavridou E, van Mil AC, et al. Pharmacodynamics of Ceftolozane Combined with Tazobactam against Enterobacteriaceae in a Neutropenic Mouse Thigh Model. Antimicrob Agents Chemother. 2016; 60: 72729.

62. Chandorkar G, Xiao A, Mouksassi MS, et al. Population pharmacokinetics of ceftolozane/tazobactam in healthy volunteers, subjects with varying degrees of renal function and patients with bacterial infections. J Clin Pharmacol. $2015 ; 55: 230-9$.

63. Xiao AJ, Caro L, Popejoy MW, et al. PK/PD Target Attainment With Ceftolozane/Tazobactam Using Monte Carlo Simulation in Patients With Various Degrees of Renal Function, Including Augmented Renal Clearance and EndStage Renal Disease. Infect Dis Ther. 2017; 6:137-48.

64. Xiao AJ, Miller BW, Huntington JA, et al. Ceftolozane/tazobactam pharmacokinetic/pharmacodynamic-derived dose justification for phase 3 studies in patients with nosocomial pneumonia. J Clin Pharmacol. 2016; 56:56-66.

65. Chandorkar G, Huntington JA, Gotfried MH, et al. Intrapulmonary penetration of ceftolozane/tazobactam and piperacillin/tazobactam in healthy adult subjects. J Antimicrob Chemother. 2012; 67:2463-9.

66. Monogue ML, Pettit RS, Muhlebach M, et al. Population Pharmacokinetics and Safety of Ceftolozane-Tazobactam in Adult Cystic Fibrosis Patients Admitted with Acute Pulmonary Exacerbation. Antimicrob Agents Chemother. $2016 ; 60: 6578-84$.

67. VanScoy BD, Mendes RE, Castanheira M et al. Relationship between ceftolozane-tazobactam exposure and selection for Pseudomonas aeruginosa resistance in a hollow-fiber infection model. Antimicrob Agents Chemother. 2014; 58:6024-31.

68. Soon RL, Lenhard JR, Bulman ZP et al. In vitro pharmacodynamic evaluation of ceftolozane/tazobactam against beta-lactamase-producing Escherichia coli in a hollow-fibre infection model. Int J Antimicrob Agents. 2017; 49:25-30.

69. Natesan S, Pai MP, Lodise TP. Determination of alternative ceftolozane/tazobactam dosing regimens for patients with infections due to Pseudomonas aeruginosa with MIC values between 4 and $32 \mathrm{mg} / \mathrm{L}$. J Antimicrob Chemother. 2017; 72:2813-16.

70. Thabit AK, Hamada Y, Nicolau DP. Physical compatibility of ceftolozane-tazobactam with selected i.v. drugs during simulated Y-site administration. Am J Health Syst Pharm. 2017; 74:e47-e54. 
71. Solomkin J, Hershberger E, Miller B, et al. Ceftolozane/tazobactam plus metronidazole for complicated intraabdominal infections in an era of multidrug resistance: results from a randomized, double-blind, phase 3 trial (ASPECT-cIAI). Clin Infect Dis. 2015; 60:1462-71.

** Results of the ASPECT-cIAI trial leading to approval of ceftolozane/tazobactam for the treatment of cIAI

72. Wagenlehner FM, Umeh O, Steenbergen J, et al. Ceftolozane-tazobactam compared with levofloxacin in the treatment of complicated urinary-tract infections, including pyelonephritis: a randomised, double-blind, phase 3 trial (ASPECT-cUTI). Lancet. 2015; 385:1949-56.

** Results of the ASPECT-cUTI trial leading to approval of ceftolozane/tazobactam for the treatment of cUTI

73. Lucasti C, Hershberger E, Miller B, et al. Multicenter, double-blind, randomized, phase II trial to assess the safety and efficacy of ceftolozane-tazobactam plus metronidazole compared with meropenem in adult patients with complicated intra-abdominal infections. Antimicrob Agents Chemother. 2014; 58:5350-7.

74. Miller B, Popejoy MW, Hershberger E, et al Characteristics and outcomes of complicated intra-abdominal infections involving Pseudomonas aeruginosa from a randomized, double-blind, phase 3 ceftolozane-tazobactam study. Antimicrob Agents Chemother. 2016; 60:4387-90.

75. Huntington JA, Sakoulas G, Umeh O, et al. Efficacy of ceftolozane/tazobactam versus levofloxacin in the treatment of complicated urinary tract infections (cUTIs) caused by levofloxacin-resistant pathogens: results from the ASPECT-cUTI trial. J Antimicrob Chemother. 2016; 71:2014-21.

76. Popejoy MW, Paterson DL, Cloutier D, et al. Efficacy of ceftolozane/tazobactam against urinary tract and intraabdominal infections caused by ESBL-producing E.coli and $K$. pneumoniae: a pooled analysis of Phase 3 clinical trials. J Antimicrob Chemother. 2017; 72:268-72.

77. Popejoy MW, Long J, Huntington JA. Analysis of patients with diabetes and complicated intra-abdominal infection or complicated urinary tract infection in phase 3 trials of ceftolozane/tazobactam. BMC Infectious Diseases. 2017; 17:316.

78. Kullar R, Wagenlehner FM, Popejoy MW, et al. Does moderate renal impairment affect clinical outcomes in complicated intra-abdominal and complicated urinary tract infections? Analysis of two randomized controlled trials with ceftolozane/tazobactam. J Antimicrob Chemother. 2017; 72: 900-5. 
79. FDA Drug Safety Communication: FDA cautions about dose confusion and medication errors for antibacterial drug Zerbaxa (ceftolozane and tazobactam). https:/www.fda.gov/Drugs/DrugSafety/ucm445919.htm. Last accessed October 15, 2017.

80. Munita JM, Aitken SL, Miller WR, et al. Multicenter Evaluation of Ceftolozane/Tazobactam for Serious Infections Caused by Carbapenem-Resistant Pseudomonas aeruginosa. Clin Infect Dis. 2017; 65:158-61.

* The largest post-marketing case series reported to date on the use of ceftolozane/tazobactam for MDR $P$. aeruginosa infections

81. Giacobbe DR, Del Bono V, Mikulska M, et al. Impact of a mixed educational and semi-restrictive antimicrobial stewardship project in a large teaching hospital in Northern Italy. Infection. 2017; 45:849-856.

82. Watkins RR, Deresinski S. Using $\beta$-lactam/ $\beta$-lactamase inhibitors for infections due to extended-spectrum $\beta$ lactamase-producing Enterobacteriaceae to slow the emergence of carbapenem-resistant Enterobacteriaceae. Expert Rev Anti Infect Ther. 2017; 15:893-895.

83. Gutierrez-Gutierrez B, Perez-Galera S, Salamanca E, et al. A Multinational, Preregistered Cohort Study of betaLactam/beta-Lactamase Inhibitor Combinations for Treatment of Bloodstream Infections Due to ExtendedSpectrum-beta-Lactamase-Producing Enterobacteriaceae. Antimicrobial agents and chemotherapy. 2016; 60:415969.

84. Kim A, Sutherland CA, Kuti JL, Nicolau DP. Optimal dosing of piperacillin-tazobactam for the treatment of Pseudomonas aeruginosa infections: prolonged or continuous infusion? Pharmacotherapy 2007; 27:1490-7.

85. Tamma PD, Han JH, Rock C, et al. Carbapenem therapy is associated with improved survival compared with piperacillin-tazobactam for patients with extended-spectrum $\beta$-lactamase bacteremia. Clin Infect Dis. 2015; $60: 1319-25$.

86. Ofer-Friedman H, Shefler C, Sharma S, et al. Carbapenems versus piperacillin-tazobactam for bloodstream infections of nonurinary source caused by extended- spectrum beta-lactamase-producing Enterobacteriaceae. Infect Control Hosp Epidemiol. 2015; 36:981-5.

87. Kauf TL, Prabhu VS, Medic G, et al. Cost-effectiveness of ceftolozane/tazobactam compared with piperacillin/tazobactam as empiric therapy based on the in-vitro surveillance of bacterial isolates in the United States for the treatment of complicated urinary tract infections. BMC Infect Dis. 2017; 17:314. 
88. Prabhu V, Foo J, Ahir H, et al. Cost-effectiveness of ceftolozane/tazobactam plus metronidazole compared with piperacillin/tazobactam as empiric therapy for the treatment of complicated intra-abdominal infections based on the in-vitro surveillance of bacterial isolates in the UK. J Med Econ. 2017; 20:840-9.

89. Kim C, Prasad V. Cancer drugs approved on the basis of a surrogate end point and subsequent overall survival: An analysis of 5 years of US Food and Drug Administration approvals. JAMA Intern Med. 2015;175:1992-4.

90. Davis C, Naci H, Gurpinar E, et al. Availability of evidence on overall survival and quality of life benefits of cancer drugs approved by the European Medicines Agency: retrospective cohort study of drug approvals from 2009-2013. BMJ. 2017;359:j4530.

91. Antimicrobial resistance surveillance in Europe. Annual report of the European Antimicrobial Resistance Surveillance Network (EARS-Net) 2015. Stockholm: ECDC, 2017. https://ecdc.europa.eu/sites/portal/files/media/en/publications/Publications/antimicrobial-resistance-europe2015.pdf. Last accessed 30 October, 2017.

92. Castón JJ, De la Torre Á, Ruiz-Camps I, et al. Salvage Therapy with Ceftolozane-Tazobactam for MultidrugResistant Pseudomonas aeruginosa Infections. Antimicrob Agents Chemother. 2017; doi: 10.1128/AAC.0213616.

93. Xipell M, Bodro M, Marco F, et al. Successful treatment of three severe MDR or XDR Pseudomonas aeruginosa infections with ceftolozane/tazobactam. Future Microbiol. 2017; doi: 10.2217/fmb-2017-0018.

94. Gentile I, Buonomo AR, Maraolo AE, et al. Successful treatment of post-surgical osteomyelitis caused by XDR Pseudomonas aeruginosa with ceftolozane/tazobactam monotherapy. J Antimicrob Chemother. 2017; 72:2678-9.

95. Dinh A, Davido B, Calin R, et al. Ceftolozane/tazobactam for febrile UTI due to multidrug-resistant Pseudomonas aeruginosa in a patient with neurogenic bladder. Spinal Cord Ser Cases. 2017; 3:17019.

96. Castaldo N, Givone F, Peghin M, et al. Multidrug-resistant Pseudomonas aeruginosa skin and soft-tissue infection successfully treated with ceftolozane/tazobactam. J Glob Antimicrob Resist. 2017; 9:100-2.

97. Dinh A, Wyplosz B, Kernéis S, et al. Use of ceftolozane/tazobactam as salvage therapy for infections due to extensively drug-resistant Pseudomonas aeruginosa. Int J Antimicrob Agents. 2017; 49:782-3.

98. Aye C, Williams M, Horvath R. Multidrug Resistant Pseudomonas Mycotic Pseudoaneurysm following Cardiac Transplant Bridged by Ventricular Assistant Device. Case Rep Infect Dis. 2017; 2017:1402320. 
99. Kurtzhalts KE, Mergenhagen KA, Manohar A, et al. Successful treatment of multidrug-resistant Pseudomonas aeruginosa pubic symphysis osteomyelitis with ceftolozane/tazobactam. BMJ Case Rep. 2017;2017.

100. Álvarez Lerma F, Muñoz Bermudez R, Grau S, et al. Ceftolozane-tazobactam for the treatment of ventilatorassociated infections by colistin-resistant Pseudomonas aeruginosa. Rev Esp Quimioter. 2017; 30:224-8.

101. Jones BM, Smith B, Bland CM. Use of Continuous-Infusion Ceftolozane/Tazobactam in a Multidrug-Resistant Pseudomonas aeruginosa Urinary Tract Infection in the Outpatient Setting. Ann Pharmacother. 2017; 51:715-6.

102. Sousa Dominguez A, Perez-Rodríguez MT, Nodar A, et al. Successful treatment of MDR Pseudomonas aeruginosa skin and soft-tissue infection with ceftolozane/tazobactam. J Antimicrob Chemother. 2017; 72:1262-3.

103. Gangcuangco LM, Clark P, Stewart C, et al. Persistent Bacteremia from Pseudomonas aeruginosa with In Vitro Resistance to the Novel Antibiotics Ceftolozane-Tazobactam and Ceftazidime-Avibactam. Case Rep Infect Dis. $2016 ; 2016: 1520404$.

104. Hernández-Tejedor A, Merino-Vega CD, Martín-Vivas A, et al. Successful treatment of multidrug-resistant Pseudomonas aeruginosa breakthrough bacteremia with ceftolozane/tazobactam. Infection. 2017; 45:115-7.

105. Vickery SB, McClain D, Wargo KA. Successful Use of Ceftolozane-Tazobactam to Treat a Pulmonary Exacerbation of Cystic Fibrosis Caused by Multidrug-Resistant Pseudomonas aeruginosa. Pharmacotherapy. 2016; 36:e154-e159.

106. Jolliff JC, Ho J, Joson J, et al. Treatment of Polymicrobial Osteomyelitis with Ceftolozane-Tazobactam: Case Report and Sensitivity Testing of Isolates. Case Rep Infect Dis. 2016; 2016:1628932.

107. Aitken SL, Kontoyiannis DP, DePombo AM, et al. Use of Ceftolozane/Tazobactam in the Treatment of Multidrugresistant Pseudomonas aeruginosa Bloodstream Infection in a Pediatric Leukemia Patient. Pediatr Infect Dis J. $2016 ; 35: 1040-2$.

108. Patel UC, Nicolau DP, Sabzwari RK. Successful Treatment of Multi-Drug Resistant Pseudomonas aeruginosa Bacteremia with the Recommended Renally Adjusted Ceftolozane/Tazobactam Regimen. Infect Dis Ther. 2016; 5:73-9.

109. Gelfand MS, Cleveland KO. Ceftolozane/Tazobactam Therapy of Respiratory Infections due to MultidrugResistant Pseudomonas aeruginosa. Clin Infect Dis. 2015; 61:853-5. 
110. Peghin M, Maiani M, Castaldo N, et al. Ceftolozane/tazobactam for the treatment of MDR Pseudomonas aeruginosa left ventricular assist device infection as a bridge to heart transplant. Infection. 2017. doi: 10.1007/s15010-017-1086-0.

111. Stokem K, Zuckerman JB, Nicolau DP, et al. Use of ceftolozane-tazobactam in a cystic fibrosis patient with multidrug-resistant Pseudomonas infection and renal insufficiency. Respir Med Case Rep. 2017; 23:8-9.

112. Dietl B, Sánchez I, Arcenillas P, et al. Ceftolozane/tazobactam in the treatment of osteomyelitis and skin and soft tissue infections due to extensively drug-resistant Pseudomonas aeruginosa: clinical and microbiological outcomes. Int J Antimicrob Agents. 2017. doi: 10.1016/j.ijantimicag.2017.11.003.

113. Leuthner KD, Kullar R, Jayakumar B, et al. Real-world Evaluation of Ceftolozane/Tazobactam (C/T) Use and Clinical Outcomes at an Academic Medical Center in Las Vegas. Open Forum Infectious Diseases. 2017; 4:S296S297. doi:10.1093/ofid/ofx163.682.

114. Pogue JM, Puzniak L, Merchant S, et al. Real-world Analysis of Prescribing Patterns and Susceptibility of Ceftolozane/Tazobactam (C/T) Treatment using an Electronic Medical Record (EMR) Database in the United States. Open Forum Infectious Diseases. 2017; 4:S287-S288. doi:10.1093/ofid/ofx163.651. 
Table 1. Activity of ceftolozane/tazobactam against $P$. aeruginos $a$ and Enterobacteriaceae reported in selected studies, including recent surveillance studies, and studies on P. aeruginosa isolates from Cystic Fibrosis (CF) patients.

\begin{tabular}{|c|c|c|c|c|c|c|}
\hline $\begin{array}{l}\text { Species } \\
\left(\text { (resistance traits }^{\text {a }}\right)\end{array}$ & $\begin{array}{l}\text { No. of isolates (country, } \\
\text { years) }\end{array}$ & $\begin{array}{l}\text { MIC range } \\
(\mathrm{mg} / \mathrm{mL})\end{array}$ & $\begin{array}{c}\mathrm{MIC}_{90} \\
(\mathrm{mg} / \mathrm{mL})\end{array}$ & $\begin{array}{l}\text { \% susceptible } \\
\text { (breakpoints) }^{\text {b }}\end{array}$ & References & Notes $^{c}$ \\
\hline P. aeruginosa & $\begin{array}{l}\mathrm{N}=3851 \\
(\mathrm{USA}, 2012-15)\end{array}$ & $0.03->32$ & 2 & 97 & $\begin{array}{l}\text { Shortridge et al. } \\
2017 \text { [28] }\end{array}$ & Ceftolozane/tazobactam more active than CAZ, FEP, PTZ, MEM \\
\hline P. aeruginosa & $\begin{array}{l}\mathrm{N}=603 \\
\text { (Europe, } 2012-15)\end{array}$ & $0.12->32$ & 4 & 92 & & $\begin{array}{l}\text { Isolates from UTI and IAI } \\
\text { Ceftolozane/tazobactam more active than CAZ, FEP, PTZ, MEM }\end{array}$ \\
\hline P. aeruginosa & $\begin{array}{c}\mathrm{N}=1099 \\
(\mathrm{UK} 2011-15)\end{array}$ & $0.12-32$ & 0.5 & & $\begin{array}{l}\text { Livermore et al. } \\
2017[25]\end{array}$ & $\begin{array}{l}\text { Isolates from BSI } \\
\text { Ceftolozane/tazobactam more active than CAZ, PTZ, IMI, MEM }\end{array}$ \\
\hline$P$. aeruginosa & $\begin{array}{l}\mathrm{N}=537 \\
(\text { Latin America, 2013-15) }\end{array}$ & & & 87 & $\begin{array}{l}\text { Pfaller et al. } \\
2017[30]\end{array}$ & Ceftolozane/tazobactam more active than CAZ, FEP, PTZ, MEM \\
\hline P. aeruginosa & $\begin{array}{l}\mathrm{N}=440 \\
\text { (Australia \& New Zealand, } \\
2013-15)\end{array}$ & $0.06->32$ & 2 & 96 & $\begin{array}{l}\text { Pfaller et al. } \\
2017 \text { [31] }\end{array}$ & Ceftolozane/tazobactam more active than CAZ, FEP, PTZ, MEM \\
\hline
\end{tabular}




$$
\mathrm{N}=363
$$

(USA, 2012-15)

$\leq 0.12->64^{\mathrm{d}}$

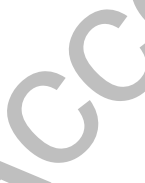

$0.25-32$

(USA, 2012-14)

\section{Isolates from BSI and LRTI}

Ceftolozane/tazobactam more active that CAZ, FEP, PTZ, MEM

Grupper et al.

Isolates from BSI, LRTI and wound infections

Ceftolozane/tazobactam more active than CAZ, FEP, PTZ, MEM
Zamorano et al.

CF patients

Ceftolozane more active than CAZ, FEP, PTZ, MEM

CF patients

Ceftolozane/tazobactam more active than CAZ, PTZ, MEM 
Enterobacteriaceae

$\mathrm{N}=15223$

(USA, 2013-16)

Enterobacteriaceae

Enterobacteriaceae

$$
\mathrm{N}=1878
$$

$\leq 0.015->32$

32

(Latin America, 2013-15)

Enterobacteriaceae

Enterobacteriaceae (ESBL non-CRE)

Enterobacteriaceae (ESBL non-CRE)

$\leq 0.015->32$

$\begin{array}{lc}\text { Enterobacteriaceae } & \mathrm{N}=1019 \\ & \begin{array}{c}\text { (Australia \& New Zealand, } \\ \text { 2013-15) }\end{array} \\ & \mathrm{N}=1450 \\ \begin{array}{l}\text { Enterobacteriaceae } \\ \text { (ESBL non-CRE) }\end{array} & \text { (USA, 2013-16) }\end{array}$

$0.06->32$

0.5

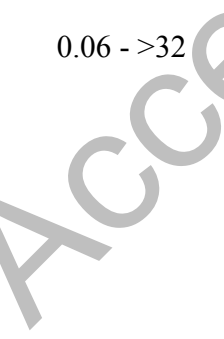

$\mathrm{N}=906$

(Europe, 2012-15)

\begin{abstract}
$0.06->32$
\end{abstract}
8

75 (E)

Pfaller et al.

2017 [29]
Ceftolozane/tazobactam more active than CAZ, FEP, PTZ, but less

active than MEM

\section{solates from UTI and IAI}

2017 [29] Ceftolozane/tazobactam more active than CAZ, FEP, PTZ, but less active than MEM

Ceftolozane/tazobactam more active than CAZ, FEP, PTZ, but less active than MEM

Ceftolozane/tazobactam more active than CAZ, FEP, PTZ, but less active than MEM

2017 [31]

Shortridge et al. 2017 [30]

Ceftolozane/tazobactam more active than CAZ, FEP, PTZ, but less active than MEM

E. coli $\mathrm{ESBL}$ ( $\mathrm{N}=966), \mathrm{S}=86 \%$; more active than $\mathrm{PTZ}(\mathrm{S}=73 \%)$

K. pneumoniae ESBL ( $\mathrm{N}=369), \mathrm{S}=63 \%$; more active than $\mathrm{PTZ}(\mathrm{S}=42 \%$ )

Isolates from urinary tract and intraabdominal infections

Ceftolozane/tazobactam more active than CAZ, FEP, PTZ, but less 
active than MEM

E. coli $\mathrm{ESBL}(\mathrm{N}=559), \mathrm{S}=88 \%$; more active than PTZ $(\mathrm{S}=67 \%)$

K. pneumoniae ESBL $(\mathrm{N}=280), \mathrm{S}=55 \%$; more active than PTZ ( $\mathrm{S}=40 \%)$

Enterobacteriaceae (ESBL non-CRE)

Enterobacteriaceae

(ESBL)

Enterobacteriaceae

(AmpC hyperprod.)

Enterobacteriaceae

(CRE)

Enterobacteriaceae

(CRE)

Enterobacteriaceae

\section{$\mathrm{N}=495$}

(Latin America, 2013-15)

$0.06->32$

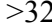

$67(\mathrm{E})$

Pfaller et al.

$2017[30]$

E. coli $\mathrm{ESBL}(\mathrm{N}=238), \mathrm{S}=87 \%$; more active than $\mathrm{PTZ}(\mathrm{S}=73 \%)$

K. pneumoniae ESBL $(\mathrm{N}=226), \mathrm{S}=46 \%$; more active than PTZ ( $\mathrm{S}=33 \%)$

\section{E. coli $\mathrm{ESBL}(\mathrm{N}=362), \mathrm{S}=53 \%$}

K. pneumoniae $\mathrm{ESBL}(\mathrm{N}=255), \mathrm{S}=26 \%$

\section{Enterobacter spp. $(\mathrm{N}=649), \mathrm{S}=18 \%$}

$2017[25]$

Shortridge et al.

2017 [38]

Pfaller et al.

Isolates from urinary tract and intraabdominal infections 
${ }^{a}$ MEM-NS, meropenem nonsusceptible; MDR, multi drug-resistant; XDR, extensively drug-resistant; ESBL, extended-spectrum beta-lactamase producers; non-CRE, non carbapenem-resistant; CRE, carbapenem-resistant

${ }^{\mathrm{b}}$ For Enterobacteriaceae: E, EUCAST breakpoints; C, CLSI breakpoints.

${ }^{\mathrm{c}}$ AMK, amikacin; CAZ, ceftazidime; FEP, cefepime; PTZ, piperacillin/tazobactam; IMI, imipenem; MEM, meropenem; ; UTI, urinary tract infections; IAI, intra-abdominal infections; BSI, bloodstream infections; LRT, lower respiratory tract infections; CF, cystic fibrosis.

${ }^{\mathrm{d}}$ Activity refers to ceftolozane tested alone. 
Table 2. Recommended doses of ceftolozane/tazobactam for the treatment of cIAI and cUTI in patients with and without renal impairment

\author{
Estimated CrCL \\ Recommended dosage
}

$(\mathrm{mL} / \mathrm{min}) *$

$>50$

$1500 \mathrm{mg}$ (1000 mg of ceftolozane and $500 \mathrm{mg}$ of tazobactam) every 8 hours

30 to 50

$750 \mathrm{mg}$ (500 mg of ceftolozane and $250 \mathrm{mg}$ of tazobactam) every 8 hours

15 to 29

$375 \mathrm{mg}$ ( $250 \mathrm{mg}$ of ceftolozane and $125 \mathrm{mg}$ of tazobactam) every 8 hours

End stage renal disease on hemodialysis

A single loading dose of $750 \mathrm{mg}(500 \mathrm{mg}$ of ceftolozane and $250 \mathrm{mg}$ of tazobactam) followed after 8 hours by a maintenance dose of $150 \mathrm{mg}(100 \mathrm{mg}$ of ceftolozane and $50 \mathrm{mg}$ of tazobactam) administered every 8 hours (on hemodialysis days, the dose should be administered at the earliest possible time following completion of hemodialysis)

Adapted from [12]. All doses are recommended for intravenous administration over 1 hour.

cIAI, complicated intra-abdominal infections; cUTI, complicated urinary tract infections; CrCL, creatinine clearance.

* According to Cockcroft-Gault formula. 
Table 3. Efficacy data from non-inferiority phase III randomized clinical trials

\begin{tabular}{|c|c|c|c|c|c|c|}
\hline Study & $\begin{array}{l}\text { Investigational drugs } \\
\text { (dosage) }\end{array}$ & $\begin{array}{l}\text { Comparators } \\
\text { (dosage) }\end{array}$ & Primary endpoint & Study population & $\begin{array}{l}\text { Cure rates } \\
\text { (cured/treated) }\end{array}$ & $\begin{array}{l}\text { \% difference } \\
(95 \% \mathrm{CI})\end{array}$ \\
\hline $\begin{array}{l}\text { ASPECT-cIAI } \\
2015 \text { [71] }\end{array}$ & $\begin{array}{l}\text { Ceftolozane/tazobactam } \\
(1000 \mathrm{mg} \text { of ceftolozane and } \\
500 \mathrm{mg} \text { of tazobactam every } \\
8 \mathrm{~h} \text {; adjusted to } 500 \mathrm{mg} \text { of } \\
\text { ceftolozane and } 250 \mathrm{mg} \text { of } \\
\text { tazobactam every } 8 \mathrm{~h} \mathrm{in} \\
\text { patients with creatinine } \\
\text { clearance of } 30-50 \\
\mathrm{~mL} / \text { minute }) \\
\text { plus } \\
\text { Metronidazole } \\
(500 \mathrm{mg} \text { every } 8 \mathrm{~h})\end{array}$ & $\begin{array}{l}\text { Meropenem } \\
(1000 \mathrm{mg} \text { every } 8 \mathrm{~h} \text {; } \\
\text { adjusted to } 1000 \mathrm{mg} \\
\text { every } 12 \mathrm{~h} \text { in patients } \\
\text { with creatinine } \\
\text { clearance of } 30-50 \\
\mathrm{~mL} / \text { minute) }\end{array}$ & $\begin{array}{l}\text { Clinical cure } \\
\text { (complete resolution } \\
\text { of infection or enough } \\
\text { improvement not } \\
\text { further requiring } \\
\text { interventions) }\end{array}$ & $\begin{array}{l}\text { MITT population* } \\
\text { Ceftolozane/tazobactam plus metronidazole } \\
\text { Meropenem } \\
\text { ME population** } \\
\text { Ceftolozane/tazobactam plus metronidazole } \\
\text { Meropenem }\end{array}$ & $\begin{array}{l}83.0 \%(323 / 389) \\
87.3 \%(364 / 417) \\
\\
94.2 \%(259 / 275) \\
94.7 \%(304 / 321)\end{array}$ & $\begin{array}{l}-4.2(-8.9 \text { to }+0.5) \\
\text { Reference } \\
-1.0(-4.5 \text { to }+2.6) \\
\text { Reference }\end{array}$ \\
\hline $\begin{array}{l}\text { ASPECT-cUTI } \\
2015[72]\end{array}$ & $\begin{array}{l}\text { Ceftolozane/tazobactam } \\
(1000 \mathrm{mg} \text { of ceftolozane and } \\
500 \mathrm{mg} \text { of tazobactam every } \\
8 \mathrm{~h} \text {; adjusted based on } \\
\text { creatinine clearance by a } \\
\text { pharmacist aware of } \\
\text { treatment allocation) }\end{array}$ & $\begin{array}{l}\text { Levofloxacin } \\
\text { ( } 750 \text { mg once daily; } \\
\text { adjusted based on } \\
\text { creatinine clearance by } \\
\text { a pharmacist aware of } \\
\text { treatment allocation) }\end{array}$ & $\begin{array}{l}\text { Composite cure } \\
\text { (clinical cure plus } \\
\text { microbiological } \\
\text { eradication of all } \\
\text { baseline } \\
\text { uropathogens) }\end{array}$ & $\begin{array}{l}\text { mMITT population } * * * \\
\text { Ceftolozane/tazobactam } \\
\text { Levofloxacin } \\
\text { Per-protocol population } * * * * \\
\text { Ceftolozane/tazobactam } \\
\text { Meropenem }\end{array}$ & $\begin{array}{l}76.9 \%(306 / 398) \\
68.4 \%(275 / 402) \\
\\
83.3 \%(284 / 341) \\
75.4 \%(266 / 353)\end{array}$ & $\begin{array}{l}+8.5(+2.3 \text { to }+14.6) \\
\text { Reference } \\
+8.0(+2.0 \text { to }+14.0) \\
\text { Reference }\end{array}$ \\
\hline
\end{tabular}


Table 4. Reported adverse events in patients treated with ceftolozane/tazobactam in randomized clinical trials

\begin{tabular}{|c|c|c|c|}
\hline Study & Phase & Investigational drug/s & $\begin{array}{l}\text { Adverse events ( } n \text { of patients with adverse events/n } \\
\text { of total patients, } \% \text { ) }\end{array}$ \\
\hline $\begin{array}{l}\text { Lucasti et al } \\
2014[73]\end{array}$ & Phase II & $\begin{array}{l}\text { Ceftolozane/tazobactam } \\
\text { plus metronidazole }\end{array}$ & $\begin{array}{l}\text { Any } A E(41 / 82,50 \%), S A E(14 / 82,17 \%) \\
\text { Pyrexia }(12 / 82,15 \%) \text {, anemia }(5 / 82,6 \%) \text {, nausea } \\
(5 / 82,6 \%) \text {, diarrhea }(4 / 82,5 \%) \text {, hypertension }(4 / 82 \text {, } \\
5 \%) \text {, vomiting }(4 / 82,5 \%) \text {, hypomagnesemia }(2 / 82, \\
2 \%) \text {, phlebitis }(2 / 82,2 \%) \text {, increased GGT }(1 / 82,1 \%)\end{array}$ \\
\hline $\begin{array}{l}\text { Solomkin et al } \\
2015 \text { [71] }\end{array}$ & $\begin{array}{l}\text { Phase III } \\
\text { (ASPECT-cIAI) }\end{array}$ & $\begin{array}{l}\text { Ceftolozane/tazobactam } \\
\text { plus metronidazole }\end{array}$ & $\begin{array}{l}\text { Any } A E(212 / 482,44 \%), \operatorname{SAE}(39 / 482,8 \%) \\
\text { Nausea }(38 / 482,8 \%) \text {, diarrhea }(30 / 482,6 \%) \text {, pyrexia } \\
(25 / 482,5 \%) \text {, insomnia }(17 / 482,4 \%) \text {, hypokalemia } \\
(14 / 482,3 \%) \text {, headache }(12 / 482,2 \%) \text {, vomiting } \\
(16 / 482,3 \%) \text {, anemia }(10 / 482,2 \%) \text {, hypertension } \\
(9 / 482,2 \%)\end{array}$ \\
\hline $\begin{array}{l}\text { Wagenlehner et al } \\
2015 \text { [72] }\end{array}$ & $\begin{array}{l}\text { Phase III } \\
\text { (ASPECT-cUTI) }\end{array}$ & Ceftolozane/tazobactam & $\begin{array}{l}\text { Any AE }(185 / 533,35 \%), S A E(15 / 533,3 \%) \\
\text { Headache }(31 / 533,6 \%) \text {, constipation }(21 / 533,4 \%) \text {, } \\
\text { increased AST and/or ALT }(18 / 533,3 \%) \text {, hypertension } \\
(16 / 533,3 \%) \text {, nausea }(15 / 533,3 \%) \text {, diarrhea }(10 / 533 \text {, } \\
2 \%) \text {, urinary tract infection }(9 / 533,2 \%) \text {, pyrexia } \\
(8 / 533,2 \%) \text {, insomnia }(7 / 533,1 \%) \text {, upper abdominal } \\
\text { pain }(7 / 533,1 \%) \text {, dizziness }(6 / 533,1 \%) \text {, myalgia } \\
(6 / 533,1 \%) \text {, vomiting }(6 / 533,1 \%) \text {, arthralgia }(1 / 533 \text {, } \\
0 \%)\end{array}$ \\
\hline
\end{tabular}

cIAI, complicated intra-abdominal infections; cUTI, complicated urinary tract infections; AE, adverse events; SAE, serious adverse events; AST, aspartate aminotransferase; ALT, alanine aminotransferase; GGT, gamma-glutamyltransferase.

Figure legends

Figure 1 legend

The side chain at the 3-position of the dihydrothiazine ring, which is responsible for the improved anti-Pseudomonas activity compared to ceftazidime is shaded in grey. 
Figure 1. The ceftolozane molecule

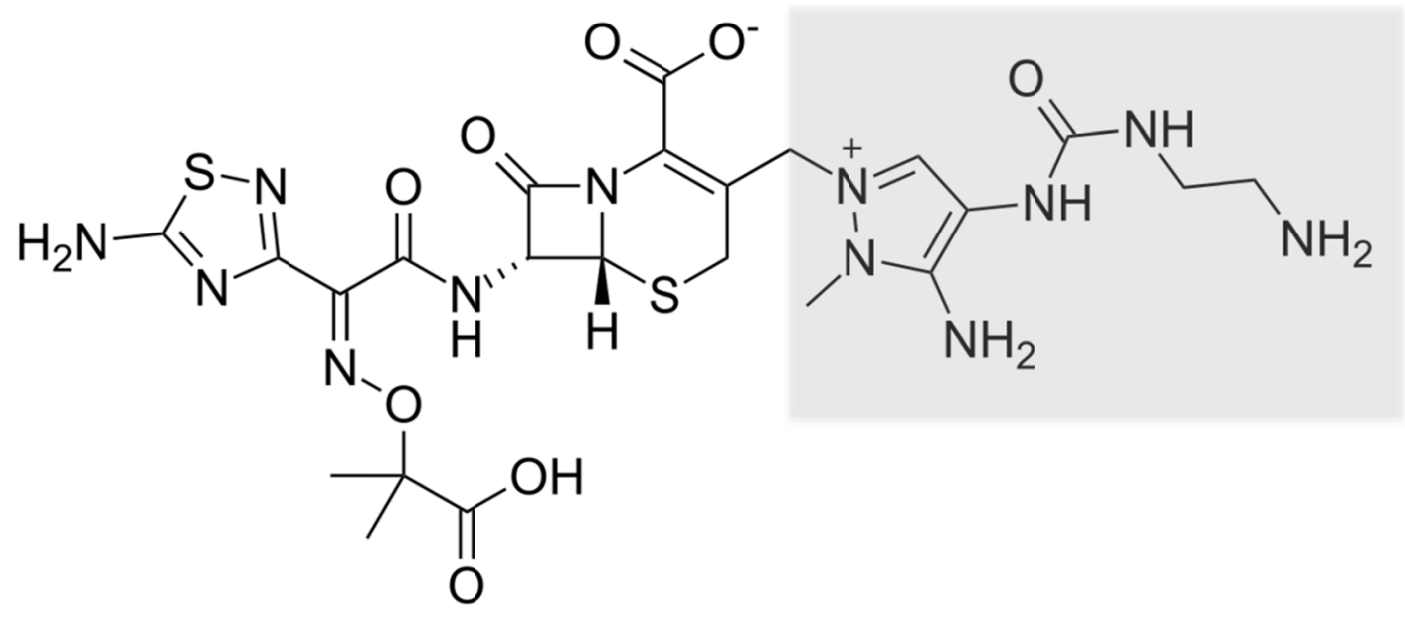

